ARTICLE

\title{
IL-1 receptor antagonist-deficient mice develop autoimmune arthritis due to intrinsic activation of IL-17-producing CCR2 $+\mathrm{V}_{\gamma} \sigma^{+} \gamma \delta$ T cells
}

Aoi Akitsu 1,2,3,4,5, Harumichi Ishigame ${ }^{1, \dagger}$, Shigeru Kakuta ${ }^{1, \dagger}$, Soo-hyun Chung ${ }^{1,5}$, Satoshi Ikeda ${ }^{1}$ Kenji Shimizu, ${ }^{1,5}$, Sachiko Kubo ${ }^{1,5}$, Yang Liu ${ }^{1, \dagger}$, Masayuki Umemura6 ${ }^{6}$ Goro Matsuzaki6, Yasunobu Yoshikai ${ }^{7}$ Shinobu Saijo ${ }^{1, \dagger} \&$ Yoichiro Iwakura $1,2,4,5$

Interleukin-17 (IL-17)-producing $\gamma \delta T(\gamma \delta 17)$ cells have been implicated in inflammatory diseases, but the underlying pathogenic mechanisms remain unclear. Here, we show that both $\mathrm{CD}^{+}{ }^{+}$and $\gamma \delta 17$ cells are required for the development of autoimmune arthritis in IL-1 receptor antagonist (IL-1Ra)-deficient mice. Specifically, activated CD4 ${ }^{+}$T cells direct $\gamma \delta$ T-cell infiltration by inducing CCL2 expression in joints. Furthermore, IL-17 reporter mice reveal that the ${\mathrm{V} \gamma 6^{+}}^{+}$subset of CCR2 ${ }^{+} \gamma \delta$ T cells preferentially produces IL-17 in inflamed joints. Importantly, because IL-1Ra normally suppresses IL-1R expression on $\gamma \delta \mathrm{T}$ cells, IL-1Ra-deficient mice exhibit elevated IL-1R expression on ${\mathrm{V} \gamma 6^{+}}^{+}$cells, which play a critical role in inducing them to produce IL-17. Our findings demonstrate a pathogenic mechanism in which adaptive and innate immunity induce an autoimmune disease in a coordinated manner.

\footnotetext{
${ }^{1}$ Laboratory of Molecular Pathogenesis, Center for Experimental Medicine and Systems Biology, The Institute of Medical Science, The University of Tokyo, Tokyo 108-8639, Japan. ${ }^{2}$ Department of Biophysics and Biochemistry, Graduate School of Science, The University of Tokyo, Tokyo 113-0032, Japan. ${ }^{3}$ Research Fellow of the Japan Society for the Promotion of Science (JSPS), Tokyo 102-0083, Japan. ${ }^{4}$ Core Research for Evolutional Science and Technology (CREST), Japan Science and Technology Agency, Saitama 332-0012, Japan. ${ }^{5}$ Division of Experimental Animal Immunology, Center for Animal Disease Models, Research Institute for Biomedical Sciences, Tokyo University of Science, Chiba 278-0022, Japan. ${ }^{6}$ Tropical Biosphere Research Center, University of the Ryukyus, Okinawa 903-0213, Japan. ${ }^{7}$ Research Center for Prevention of Infectious Diseases, Medical Institute of Bioregulation, Kyushu University, Fukuoka 812-8582, Japan. † Present addresses: RIKEN Center for Integrative Medical Sciences, Kanagawa 230-0045, Japan (H.I.); Department of Biomedical Science, Graduate School of Agricultural and Life Sciences, The University of Tokyo, Tokyo 113-8657, Japan (S.K.); Renji Hospital Clinical Stem Cell Research Center, Shanghai Jiao Tong University School of Medicine, Shang Hai 200127, China (Y.L.); Department of Molecular Immunology, Medical Mycology Research Center, Chiba University, Chiba 263-8522, Japan (S.S.). Correspondence and requests for materials should be addressed to Y.I. (email: iwakura@rs.tus.ac.jp).
} 
nterleukin (IL)-17 plays important roles in the development of autoimmune diseases, such as rheumatoid arthritis and psoriasis, by inducing expression of proinflammatory cytokines and chemokines, recruiting neutrophils and activating $\mathrm{T}$ cells and $\mathrm{B}$ cells ${ }^{1,2}$. Although helper CD4 ${ }^{+} \mathrm{T}$ (Th17) cells are well-known producers of IL-17 that contribute to the development of autoimmune diseases, recent studies showed that innate immune cells and innate-like cells are also important sources of IL-17 in local inflammatory tissues ${ }^{3,4}$. Mouse autoimmune disease models have revealed that IL-17-producing $\gamma \delta \mathrm{T}(\gamma \delta 17)$ cells are an important innate source of IL-17 (refs 5-13). In collagen-induced arthritis, experimental autoimmune encephalomyelitis and psoriasis-like skin inflammation, the synergy between $\gamma \delta 17$ and $\alpha \beta$ T cells is important for disease development ${ }^{5,6,11,14}$, but it remains unclear how $\gamma \delta 17$ cells induce tissue-specific inflammation.

$\gamma \delta 17$ cells share many characteristics with Th17 cells. However, in contrast to Th17 cells in which differentiation in the periphery is required for IL-17 production, the functional potential of $\gamma \delta 17$ cells is already determined during intrathymic development ${ }^{15-17}$. These $\gamma \delta$ thymocytes, which express the transcription factor ROR $\gamma \mathrm{t}$ and the signature cytokine receptor IL-23R ${ }^{18}$, leave the thymus as functionally committed cells ${ }^{19}$. Therefore, $\gamma \delta$ T cells produce IL-17 directly following stimulation with IL-1 $\beta$ and IL23 without T cell receptor (TCR) stimulation in the periphery ${ }^{5,13}$. Although the expression of IL-23R on $\gamma \delta 17$ cells is constitutive ${ }^{5}$, expression of IL-1R in the periphery is tissue-type dependent ${ }^{20}$. Ill $r 1^{-1-}$ mice or anti-IL-1R monoclonal antibody (mAb) treatment abrogates IL-17 production in $\gamma \delta \mathrm{T}$ cells ${ }^{11,20}$, suggesting that IL-1R expression plays a critical role in IL-17 production. However, the regulatory mechanism of IL-1R expression remains unclear. In addition to ROR $\gamma \mathrm{t}$, transcription factors such as Blk ${ }^{21}$, Hes-1 (ref. 22), NFKB ${ }^{23}$, SOX4 and SOX13 (ref. 24) are also required for $\gamma \delta 17$ cell development.

In mice, the TCR $\gamma$ locus consists of seven $V \gamma(V \gamma 1-V \gamma 7)$ genes that are closely correlated with effector functions, although in most strains $\mathrm{V} \gamma 3$ is a pseudogene ${ }^{25}$. IL-17 is produced by $\mathrm{V} \gamma 4^{+}$ and $\mathrm{V} \gamma 6^{+} \gamma \delta \mathrm{T}$ cells ${ }^{26}$ (Heilig and Tonegawa's nomenclature ${ }^{27}$ ). Although overall gene expression patterns are similar between these two subsets ${ }^{18}$, each subset has distinct features. $\mathrm{V} \gamma 6^{+} \gamma \delta \mathrm{T}$ cells express the invariant $\mathrm{V} \gamma 6 / \mathrm{V} \delta 1 \mathrm{TCR}$, develop only in the lateembryonic thymus and preferentially localize in the uterus, vagina, lung, dermis and peritoneal cavity ${ }^{28,29}$. On the other hand, $\mathrm{V} \gamma 4^{+}$ $\gamma \delta \mathrm{T}$ cells have a more diverse TCR repertoire, and develop in both foetal and adult thymus. Subsequently, they circulate in blood and reside in the dermis and secondary lymphoid organs ${ }^{30}$. However, the differences between the pathogenic roles of $\mathrm{V} \gamma 6^{+}$ and $\mathrm{V} \gamma 4^{+} \gamma \delta 17$ cells, particularly the contribution of $\mathrm{V} \gamma 6^{+} \gamma \delta 17$ cells to inflammatory diseases, remain unclear.

The mechanism of $\gamma \delta 17$ cell migration into inflammatory sites is also poorly understood. Recent gene array analysis showed that the expression of chemokine receptors such as CCR6, CCR2 and CXCR6 is upregulated in $\gamma \delta 17$ thymocytes ${ }^{18}$. Moreover, CCR6 expression is often used as a marker of $\gamma \delta 17$ cells $^{17}$. However, it remains unknown whether these chemokine receptors function in $\gamma \delta 17$ cell migration.

IL-1 receptor antagonist (IL-1Ra, gene symbol: Illrn) is an endogenous inhibitor of IL-1 activity that competes with IL- $1 \alpha$ and IL-1 $\beta$ for IL-1R binding. IL-1Ra-deficient $\left(I l 1 \mathrm{rn}^{-/-}\right)$mice spontaneously develop arthritis in an IL-17- and T-celldependent manner ${ }^{31-33}$, suggesting that excess IL-1 signalling caused by IL-1Ra deficiency induces IL-17 production from $\mathrm{T}$ cells and the development of arthritis. Here, we found that $\gamma \delta 17$ cells are the main producers of IL-17 in joints of $I l 1 \mathrm{rn}^{-/-}$mice, and that recruitment of CCR2 ${ }^{+} \gamma \delta \mathrm{T}$ cells to the joints via induction of CCL2 by $\mathrm{CD}^{+}{ }^{+} \mathrm{T}$ cells is important for the development of arthritis. Both ${\mathrm{V} \gamma 6^{+}}^{+}$and $\mathrm{V} \gamma 4^{+} \gamma \delta \mathrm{T}$ cells were recruited to the joints, but only the $\mathrm{V} \gamma 6^{+}$subset efficiently produced IL-17, because Ill $r^{-1}-\mathrm{V} \gamma 6^{+}$cells intrinsically expressed high levels of IL-1R due to the loss of downregulation of IL-1R expression by IL-1Ra. These observations provide novel insights into the pathogenic mechanism underlying the development of autoimmune arthritis in $I l 1 r n^{-1-}$ mice.

\section{Results}

$\gamma \delta \mathrm{T}$ cells mainly produce IL-17 in $\mathrm{Il1rn}^{-/-}$mouse joints. We analysed IL-17-producing cells in arthritic $I 11 \mathrm{rn}^{-1-}$ mice. Both $\gamma \delta 17$ cell and Th17 cell populations were elevated in draining lymph nodes (LNs) of affected joints (Fig. 1a,b), whereas proportions of $\mathrm{IL}-17^{+} \mathrm{CD} 8{ }^{+} \mathrm{T}$ cells and IL- $17^{+} \mathrm{DX} 5{ }^{+} \mathrm{T}$ cells were unchanged (Supplementary Fig. 1). Notably, most joint-infiltrating IL-17-producing cells were $\gamma \delta$ T cells, whereas Th17 cells were rare (Fig. 1c). Moreover, immunofluorescence staining revealed that IL-17 in the joints was primarily expressed in $\gamma \delta \mathrm{T}$ cells (Fig. 1d). These observations suggest that $\gamma \delta 17$ cells play a pathogenic role in the development of arthritis in $I l 1 \mathrm{rn}^{-/-}$mice.

$\gamma \delta$ and $\mathrm{CD}^{+} \mathrm{T}$ cells are involved in arthritis development. To analyse the pathogenic roles of $\gamma \delta$ T cells and CD4 ${ }^{+} \mathrm{T}$ cells, we injected either anti- $\gamma \delta$ TCR or anti-CD4 $\mathrm{mAb}$ into ${\text { Ill } \mathrm{rn}^{-}}^{-}-$ mice before onset of disease. Both antibody treatments significantly suppressed the incidence of arthritis (Fig. 2a,b). Although the severity scores, determined by the swelling and ankylosing changes of the affected ankles of antibody-treated mice, were similar to those of untreated mice (Supplementary Fig. 2a,b), the microscopic histological scores significantly decreased following treatment with anti- $\gamma \delta$ TCR mAb (Fig. 2c,d). Anti- $\gamma \delta$ TCR mAb treatment depleted $70-90 \%$ of $\gamma \delta$ T cells at early time points, but the population gradually recovered (Supplementary Fig. 2c), probably due to the development of antibodies against this mAb. Nonetheless, the anti- $\gamma \delta$ TCR mAb treatment greatly decreased the $\gamma \delta 17$ population (Fig. 2e; Supplementary Fig. 2d), suggesting that anti- $\gamma \delta$ TCR mAb effectively depleted $\gamma \delta 17$ cells, at least at earlier times. IL-17 production in the $\gamma \delta \mathrm{TCR}^{-}$population was not elevated in these mice (Supplementary Fig. 2d). Most populations of $\mathrm{CD}_{4}^{+}$ $\mathrm{T}$ cells, including Th17 cells, remained depleted in $I l 1 \mathrm{rn}^{-/-}$ mice on day 11 after anti-CD4 mAb treatment (Fig. 2f; Supplementary Fig. 2e). These results suggest that both $\gamma \delta$ T cells and $\mathrm{CD} 4{ }^{+} \mathrm{T}$ cells are involved in the development of arthritis in Ill $^{-1-}$ mice. However, arthritis developed normally in Tcrd ${ }^{-1-}$ Illrn ${ }^{-1-}$ mice (Supplementary Fig. 2f), and IL-17producing $\mathrm{CD}^{-}{ }^{-} \mathrm{CD}^{-} \gamma \delta \mathrm{TCR}^{-} \mathrm{T}$ cells were increased in the LNs and joints of these mice (Supplementary Fig. 2g).

Both $\gamma \delta 17$ and $\mathrm{CD} 4{ }^{+} \mathrm{T}$ cells collaborate to develop arthritis. Next, we directly examined the pathogenic role of $\gamma \delta$ T cells and $\mathrm{CD} 4{ }^{+} \mathrm{T}$ cells by adoptive cell transfer. $\gamma \delta \mathrm{T}$ cells derived from $\mathrm{Cd}^{-1-}$ Ill $\mathrm{rn}^{-1-}$ mice and/or $\mathrm{CD} 4{ }^{+} \mathrm{T}$ cells derived from Tcrd ${ }^{-1-}$ Ill $\mathrm{rn}^{-1-}$ mice were transferred into scid/scid mice. We found that scid/scid mice that received transfer of wholeIll $r n^{-1-}$ T cells or a mixture of $\gamma \delta$ and $\mathrm{CD} 4{ }^{+} \mathrm{T}$ cells developed arthritis, whereas those that received transfer of $\gamma \delta$ or $\mathrm{CD} 4^{+}$ $\mathrm{T}$ cells alone did not (Fig. $2 \mathrm{~g}$ ). Instead, development of inflammation was observed in other organs, such as the colon and dermis, when $\gamma \delta \mathrm{T}$ cells alone were transferred (Supplementary Fig. 2h). When total T cells or a mixture of $\gamma \delta$ and CD $4^{+} \mathrm{T}$ cells were transferred, $\gamma \delta 17$ cells were present in arthritic joints (Fig. 2h); however, no $\gamma \delta \mathrm{T}$ cells were located in the joints when $\gamma \delta \mathrm{T}$ cells were transferred alone. When $\mathrm{CD} 4{ }^{+} \mathrm{T}$ cells were transferred, no Th17 cells were observed in the joints, although 
$a_{\text {LN }}$

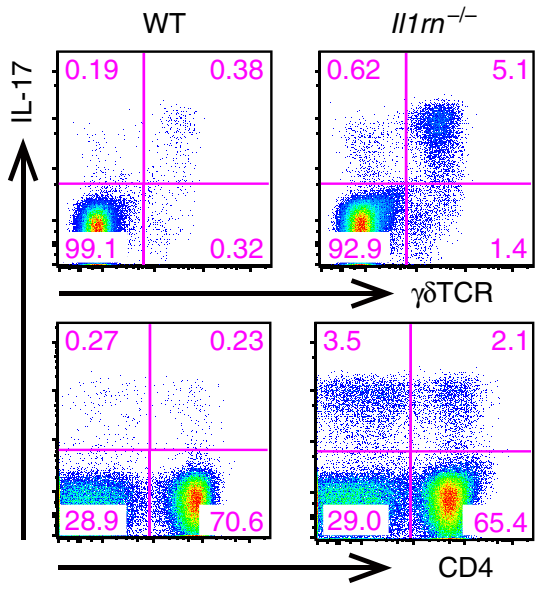

C

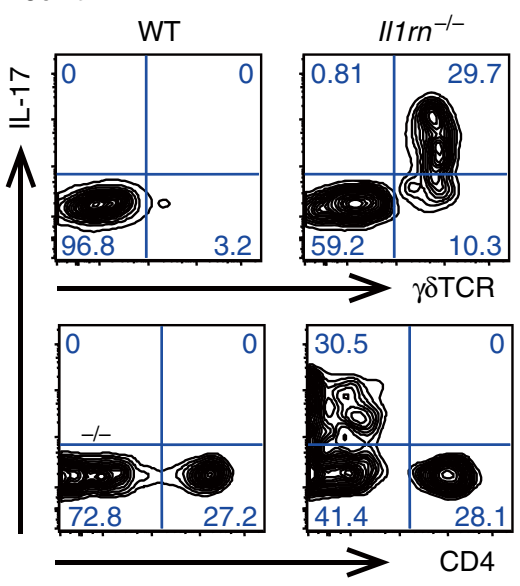

b
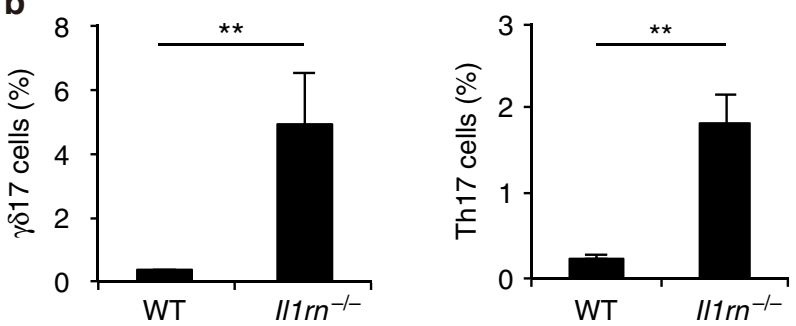

d
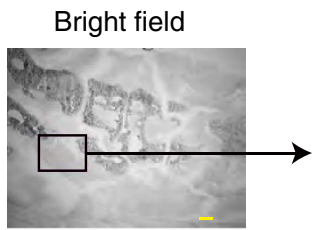

Bright field

Fluorescence

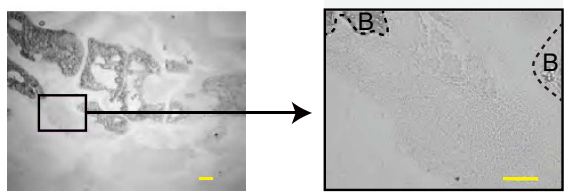

B

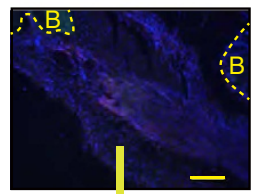

IL-17

$\gamma \delta$ TCR

DAPI

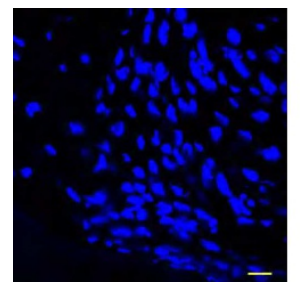

IL-17

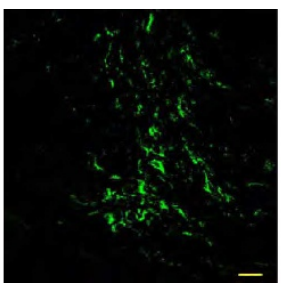

$\gamma \delta$ TCR

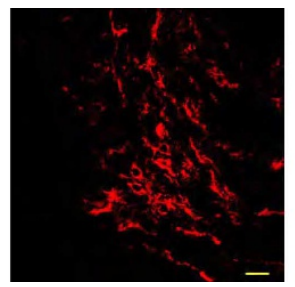

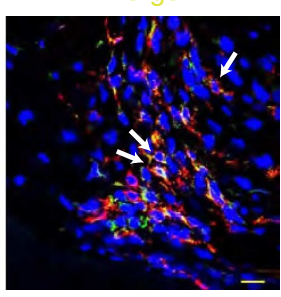

Figure $1 \mid \gamma \delta$ T cells are the main source of IL-17 in the inflamed joints of IIrn ${ }^{-1}$ - mice. (a-c) Flow cytometry of LN cells from WT ( $n=3$ ) and arthritic $\| 11 r^{-/}-$mice $(n=3)$ (a) or joint-infiltrating cells from WT (pool of five mice) and arthritic $\| 11 r^{-/}$- mice (pool of two mice) (c). All cells were stimulated with $\mathrm{P} / \mathrm{I}$ for $5 \mathrm{~h}$, and then stained for intracellular IL-17. Numbers refer to percent cells in CD3 $\varepsilon^{+}$cells. Quantification of IL-17 ${ }^{+} \gamma \delta \mathrm{TCR}^{+}$and IL-17 ${ }^{+} \mathrm{CD}^{+}$ in $\mathrm{CD} 3 \varepsilon^{+}$cells are shown $(\mathbf{b}) .{ }^{\star \star} P<0.01$ versus WT mice (unpaired Student's $t$-test). Data show mean \pm s.e.m. (d) Frozen sections of arthritic joints of $\| 17 r^{-1}-$ mice were co-stained with anti-IL-17 Ab (green), anti- $\gamma \delta$ TCR Ab (red) and 4,6-diamidino-2-phenylindole (DAPI) (blue). Sections were observed under a fluorescence microscope (top and middle panels, scale bars, $100 \mu \mathrm{m}$ ), and a confocal microscope (bottom panels, scale bars, $10 \mu \mathrm{m}$ ).

$\mathrm{B}$, bone. IL-17 ${ }^{+} \gamma \delta \mathrm{TCR}^{+}$cells are shown by white arrows. Similar results were obtained in six other $I / 1 \mathrm{rn}-/-$ mice. All data except $\mathbf{d}$ are representative of $>5$ independent experiments.

IL- $17^{-} \mathrm{CD} 4^{+} \mathrm{T}$ cells were found (Fig. $2 \mathrm{~h}$ ). In contrast to the joints, $\gamma \delta 17$ and Th17 cells were observed in LNs of scid/scid mice that received transfer of $\gamma \delta$ and $\mathrm{CD} 4^{+} \mathrm{T}$ cells, respectively
(Supplementary Fig. 2i). Thus, Illirn ${ }^{-1-} \mathrm{CD}^{+} \mathrm{T}$ cells are required for the recruitment of $\gamma \delta \mathrm{T}$ cells to the joints, and $\gamma \delta$ $\mathrm{T}$ cells are required for the production of IL-17. 
Joint-infiltrating $\gamma \delta 17$ cells predominantly express CCR2. To analyse $\gamma \delta 17$ cells in joints, we generated an IL-17 reporter $\left(I l 7^{g / g}\right)$ mouse, in which IRES-eGFP was inserted into the $I l 17 a$ locus without affecting IL-17 production (Supplementary Fig. 3a,b). Similar to Il1 $\mathrm{rn}^{-1-}$ mice, Il1 $7^{g / g} I l 1 \mathrm{rn}^{-/-}$mice spontaneously developed arthritis (Supplementary Fig. 3c). Green fluorescent protein (GFP) expression correlated with intracellular IL-17 expression in joint-infiltrating cells from $1 l 17^{g / g} I l 1 m^{-/-}$ mice after phorbol myristate acetate and ionomycin $(\mathrm{P} / \mathrm{I})$ stimulation (Supplementary Fig. 3d), indicating that GFP expression accurately reflects IL-17 expression. Consistent with intracellular IL-17 staining in Ill $\mathrm{rn}^{-/-}$mice (Fig. 1c), joint GFP

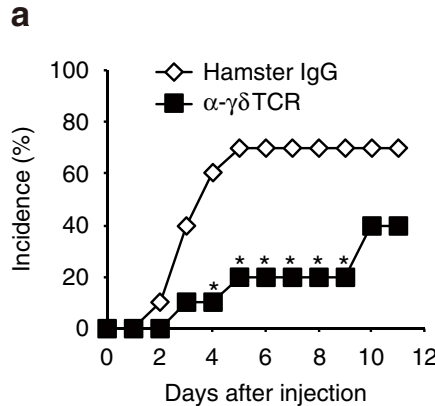

b

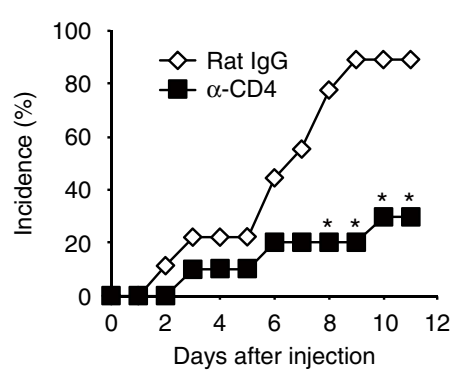

C

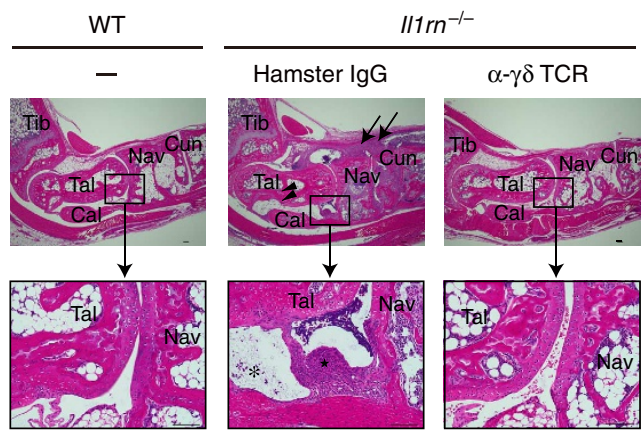

d

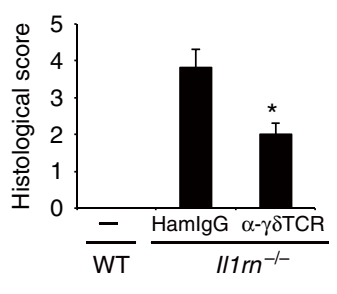

e

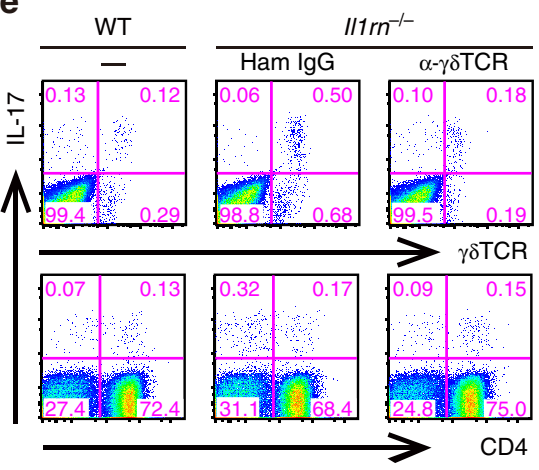

f

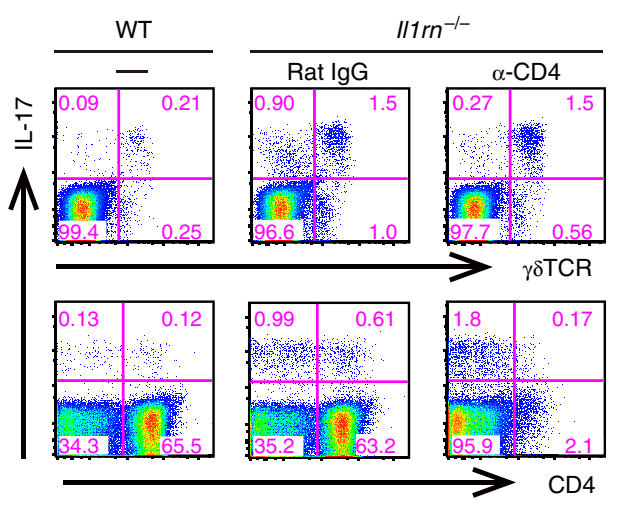

g

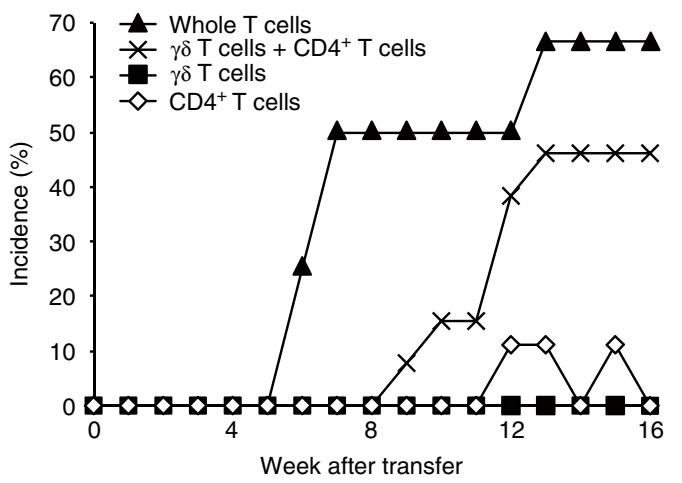

h

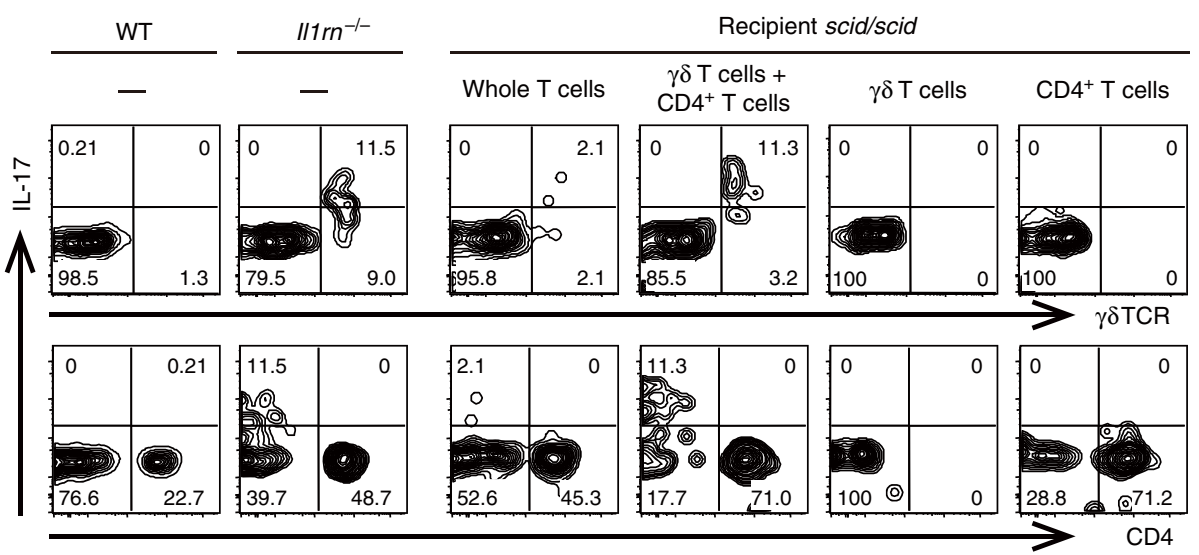


expression was mostly limited to $\gamma \delta \mathrm{T}$ cells (Supplementary Fig. 3e). GFP expression was detectable without any stimulation in joints, whereas only few were detected in LNs (Supplementary Fig. 3f,d), suggesting that $\gamma \delta 17$ cells were activated in joints.

Several chemokine receptors, including CCR2, CXCR6 and CCR6, were expressed on joint-infiltrating $\gamma \delta$ T cells in Ill $r^{-1-}$ mice (Supplementary Fig. 4a). In particular, almost all $\gamma \delta \mathrm{T}$ cells expressed CCR2, but not CCR5, CXCR4 or CCR9. Using these Il1 $\mathrm{g}^{g} / \mathrm{g}$ Il1 $\mathrm{rn}^{-1}$ - mice, we found that about $95 \%$ of $\gamma \delta 17$ cells expressed CCR2, and that relatively large proportions of $\gamma \delta 17$ cells also expressed CXCR6 and CCR6 (Fig. 3a).

Next, we examined chemokine expression in joints. Consistent with our previous microarray analysis ${ }^{34}$, expression of $\mathrm{Ccl} 2$ (ligand for CCR2), Cxcl16 (ligand for CXCR6), Ccl5 (ligand for CCR5) and Cxcl12 (ligand for CXCR4) was significantly elevated in joints of Ill $\mathrm{rn}^{-1-}$ mice relative to wild-type (WT) mice, whereas expression of Ccl20 (ligand for CCR6) was unchanged (Fig. 3b). Moreover, we detected moderate levels of $\gamma \delta$ T-cell infiltration in the non-arthritic joints of $I l 17 a^{-1-} I_{l 11 n^{-1-}}$ mice $^{32}$. In these mice, $\gamma \delta \mathrm{T}$ cells expressed high levels of CCR2, but not CXCR6 (Fig. 3c), indicating that the accumulation of CCR2 ${ }^{+} \gamma \delta \mathrm{T}$ cells is not a result of inflammation. These observations suggest that the CCL2-CCR2 axis is involved in the recruitment of $\gamma \delta \mathrm{T}$ cells into joints.

Illm $n^{-1-} \mathrm{CD}^{+}$cells induce $\mathrm{Ccl} 2$ expression in joints. CCR2 ${ }^{+} \gamma \delta \mathrm{T}$ cells accumulated preferentially in arthritic joints, but not other organs, of $\mathrm{Illm}^{-1}$ mice (Fig. 3d; Supplementary Fig. 4b). Consistent with this, expression of Ccl2 (Fig. 3e), but not Ccl20 (Supplementary Fig. 4c), was elevated in joints of ${\mathrm{Ill} \mathrm{rn}^{-1-}}^{-1}$ mice. Moreover, expression of $\mathrm{Ccl} 2$, but not $\mathrm{Cxcl16}$, was specifically elevated in joints of scid/scid mice when Illirn ${ }^{-1-}$ $\mathrm{CD}^{+} \mathrm{T}$ cells, but not $\gamma \delta \mathrm{T}$ cells, were transferred (Fig. 3f,g). Thus, activated $\mathrm{CD} 4{ }^{+} \mathrm{T}$ cells induce $\mathrm{Ccl} 2$ expression in synovial resident cells and cause migration of $\mathrm{CCR} 2{ }^{+} \gamma \delta \mathrm{T}$ cells.

CCL2 recruits $\gamma \delta \mathrm{T}$ cells to joints and induces arthritis. To determine whether elevated CCL2 expression in joints causes $\gamma \delta 17$ cell accumulation and disease development in Il1rn ${ }^{-1-}$ mice, we injected anti-CCL2 $\mathrm{mAb}$ into $I l 17^{g / g} / 111 \mathrm{rn}^{-1-}$ mice and analysed joint-infiltrating $\gamma \delta \mathrm{T}$ cells. Anti-CCL2 mAb treatment significantly suppressed development of arthritis in $I l 17^{g / g} / 11 r^{-1}-$ mice (Fig. 4a; Supplementary Fig. 5), suggesting an important role for CCL2 in pathogenesis. The frequencies of $\gamma \delta \mathrm{T}$ cells and CCR2 ${ }^{+} \gamma \delta \mathrm{T}$ cells were significantly reduced in joints of non-arthritic mice after $\mathrm{mAb}$ treatment (Fig. $4 \mathrm{~b}-\mathrm{e}$ ), indicating that CCL2 is responsible for recruitment of CCR2 ${ }^{+} \gamma \delta$ $\mathrm{T}$ cells into joints. In mAb-treated non-arthritic mice, only a few $\mathrm{GFP}^{+} \gamma \delta \mathrm{T}$ cells were detected (Fig. 4d,f), suggesting a pathogenic role for joint-infiltrating $\gamma \delta 17$ cells in development of arthritis. Notably, when $\mathrm{GFP}^{+}{ }^{+} \delta$ T cells were gated, CCR2 was expressed at similar levels even in cells from anti-CCL2 mAbtreated non-arthritic mouse joints (Fig. 4g,h), suggesting that CCR2 expression in $\gamma \delta 17$ cells is required for the development of arthritis. On the other hand, the correlation between CXCR6 expression and disease development suggests that CXCR6 expression is a result of inflammation (Fig. 4i,j). These data indicate that CCR2 ${ }^{+} \gamma \delta \mathrm{T}$ cells migrate into joints in response to high levels of CCL2 in $\mathrm{Illm}^{-} \mathrm{P}_{-}$mouse joints, leading to development of arthritis.

IL-1Ra suppresses IL-1R expression on $\gamma \delta$ T cells. Next, we analysed the mechanism of IL-17 induction in $\gamma \delta \mathrm{T}$ cells. Consistent with a previous report ${ }^{35}$, IL-23 alone or IL-23 plus IL-1 $\beta$ induced IL-17 production from magnetic-activated cell sorting (MACS)-purified splenic $\gamma \delta$ T cells (purity: $80 \%$ ) (Fig. 5a). However, MACS-purified Illa ${ }^{-1-} I_{11 b^{-7-}} \gamma \delta \mathrm{T}$ cells or fluorescence-activated cell sorting (FACS)-purified WT $\gamma \delta \mathrm{T}$ cells (purity: >99\%) did not respond to IL-23 alone, and IL-1 $\beta$ was required to induce IL-17 (Fig. 5a,b), suggesting that IL-1 $\beta$ is essential for the IL-17 induction in $\gamma \delta \mathrm{T}$ cells. Consistent with these results, the development of arthritis was completely

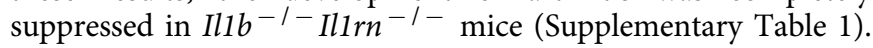

We then analysed the effects of IL- $1 \beta$ and IL-23 on expression of genes encoding transcription factors characteristic of Th17 cells, such as ROR $\gamma \mathrm{t}, \mathrm{ROR} \alpha, \mathrm{I} \kappa \mathrm{B} \zeta$ and BATF. ROR $\gamma \mathrm{t}$ expression in $\gamma \delta \mathrm{T}$ cells was drastically increased by addition of IL-1 $\beta$ and IL-23 together, but only marginally by IL-1 $\beta$ or IL-23 alone (Supplementary Fig. 6a). A similar effect was observed on ROR $\alpha$ expression. IKB $\zeta$ and BATF were induced by IL- $1 \beta$ alone, and the increase in their expression was synergistically enhanced by the addition of IL-23.

IL-23 remarkably increased IL-1R expression on $\gamma \delta \mathrm{T}$ cells (Fig. 5c,d; Supplementary Fig. 6b). On the other hand, IL-23R was expressed on unstimulated $\gamma \delta$ T cells from WT, Illa $a^{-1-} b^{-1-}$ and Illrn ${ }^{-1-}$ mice, and its expression was not enhanced by the addition of IL-1 $\beta$ (Fig. 5e). IL-1 $\beta$ or IL-23 signalling alone was not sufficient for induction of IL-17; instead, synergistic

Figure 2 | Collaboration between $\mathbf{C D 4}{ }^{+} \mathbf{T}$ cells and $\boldsymbol{\gamma} \boldsymbol{\delta 1 7}$ cells is important for the development of arthritis. (a,b) Suppression of arthritis development in $\| 17 r^{-/}$- mice after treatment with anti- $\gamma \delta$ TCR (a) or anti-CD4 (b) mAb. Non-arthritic $/ 17 r^{-/-}$mice at the age of 4 weeks were injected on days 0,3 , 7 and 10 (ages of $28,31,35$ and 38 days) with anti- $\gamma \delta \operatorname{TCR} \operatorname{mAb}(\boldsymbol{a}, n=10)$ or isotype-matched hamster $\operatorname{lgG}(\diamond, n=10)(\mathbf{a})$, or with anti-CD4 mAb $(\boldsymbol{\square}, n=10)$ or isotype-matched rat $\lg G(\diamond, n=9)(\mathbf{b}) .{ }^{\star} P<0.05$ versus control IgG, assessed by the $\chi^{2}$-test. (c,d) Non-arthritic $/ 17 r n{ }^{-/}-$mice at the age of 20 days were injected with anti- $\gamma \delta$ TCR mAb or hamster lgG every 3 days (ages of 20, 23 and 26 days), and mice were killed at the age of 27 days. Representative haematoxylin and eosin-stained sections of ankle joints in non-treated WT mouse (left column, $n=6$ ) and $I 17 \mathrm{rn}^{-/}-\mathrm{mouse} \mathrm{treated}$ with control hamster IgG (middle column, $n=6$ ) or $\alpha-\gamma \delta$ TCR mAb (right column, $n=5$ ) are shown. Synovial cell proliferation and inflammatory cell infiltration (arrows), bone erosion (arrowheads), fibrin clots $\left(^{\star}\right)$ and pannus formation $(\star)$ in control I/1rn ${ }^{-/-}$mouse (middle column) are indicated. Scale bars, $100 \mu \mathrm{m}$. Tib, tibia; Tal, talus; Cal, calcaneum; Nav, navicular bone; Cun, cuneiform bone (c). (d) The means of histological scores are shown. ${ }^{\star} P<0.05$ versus $\| 11 \mathrm{rn}^{-/}-$mice treated with hamster IgG. (e,f) Flow cytometry of LN cells from antibody-treated $/ 17 r^{-} /-$mice. Cells were collected from $/ 17 r n^{-/}-$ mice, 8 days after the first injection with anti- $\gamma \delta$ TCR mAb or hamster IgG-treated (e) or 11 days after the first treatment with anti-CD4 mAb or rat IgG (f) or from non-treated WT mice. Cells were stimulated with P/I for $5 \mathrm{~h}$, and then stained for intracellular IL-17. Numbers refer to percentages in CD3 $\varepsilon^{+}$cells. (a-f) Data are representative of two independent experiments. $(\mathbf{g}, \mathbf{h})$ scid/scid mice at the age of 4 weeks were transferred with $\gamma \delta T$ cells from

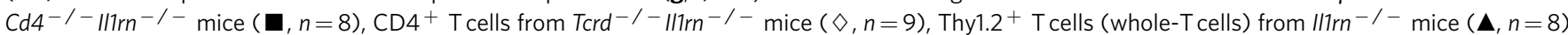
or $\gamma \delta$ T cells from $C d 4^{-/-} \| 11 r^{-/}-$mice plus CD4 ${ }^{+}$T cells from Tcrd ${ }^{-/}-\| 17 n^{-/-}$mice $(x, n=13)$. Incidence of arthritis is shown (g). Flow cytometry of the joint-infiltrating cells of scid/scid mice after 18 weeks of transfer, or age-matched and non-treated WT or $/ 17 r^{-/-}$mice (h). Cells were stimulated with $\mathrm{P} / \mathrm{I}$ for $5 \mathrm{~h}$, and then stained for intracellular IL-17. Numbers refer to percentage in $\mathrm{CD} 3 \varepsilon^{+}$cells. Data are pooled from $\mathbf{g}$ or representative of (h) two independent experiments. 
activation by IL-1 $\beta$ and IL-23 was required (Fig. 5f; Supplementary Fig. 6c).

IL-1R expression induced by IL-23 was suppressed by the addition of exogenous IL-1Ra, and IL-1R expression was elevated on Il1rn ${ }^{-1-} \gamma \delta \mathrm{T}$ cells (Fig. 5c,d), indicating that IL-23 and IL-1Ra reciprocally regulates IL-17 production by regulating IL-1R expression. Consistent with the elevation in IL-1R expression, IL-17 production in response to IL-23 and IL-1 $\beta$ a Gated on $\gamma \delta$ TCR

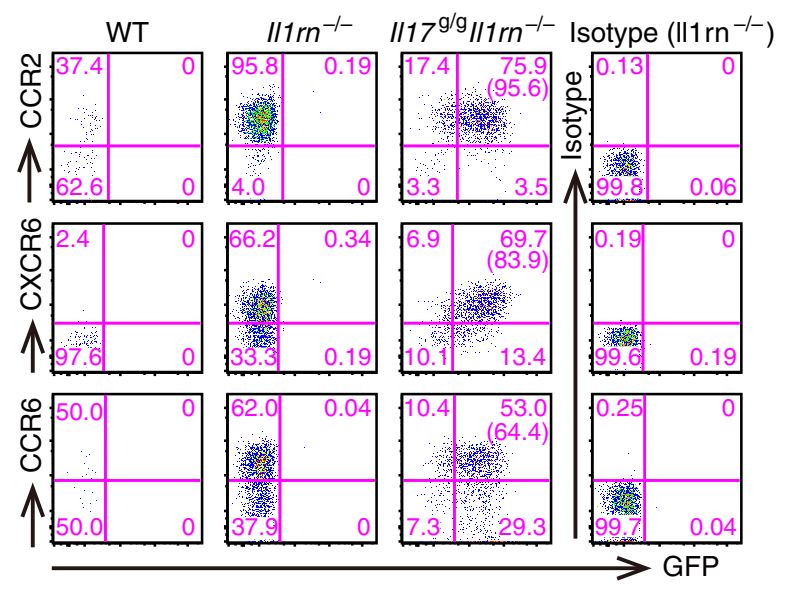

$$
\text { C }
$$

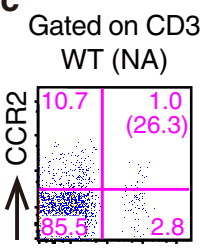

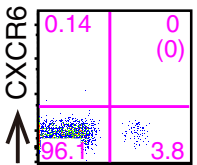

$\| / 1 \mathrm{rn}^{-/-}$(A) $/ / 17 \mathrm{a}-/-/ / 1 \mathrm{rn}^{-/-}$(NA) Isotype $\left(/ / 1 \mathrm{rn}^{-/-}\right)$
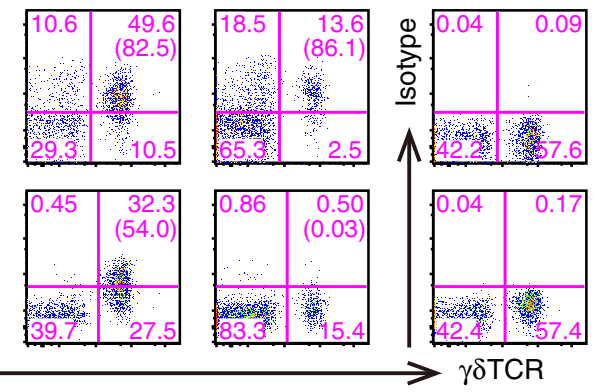

b
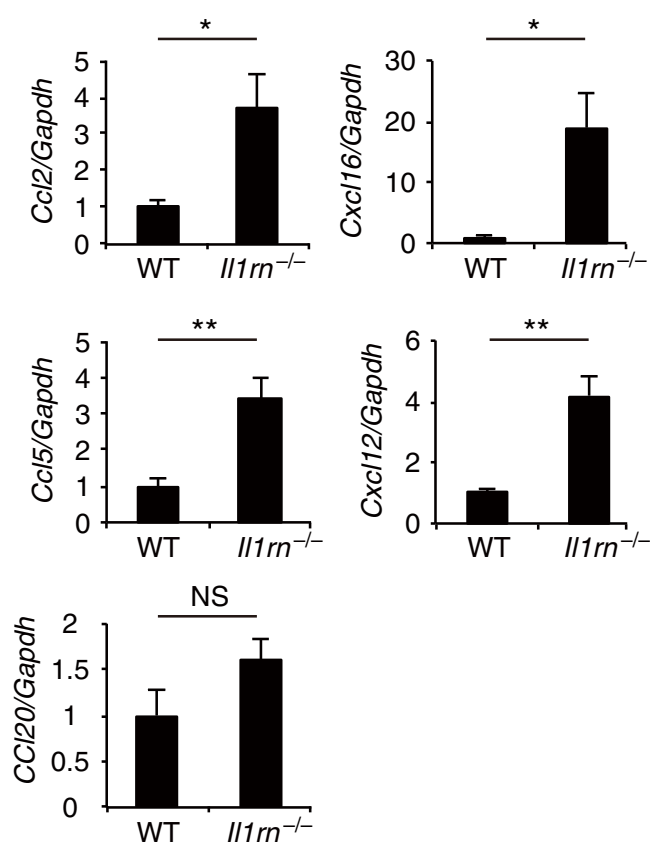

d

Gated on $\gamma \delta$ T cells
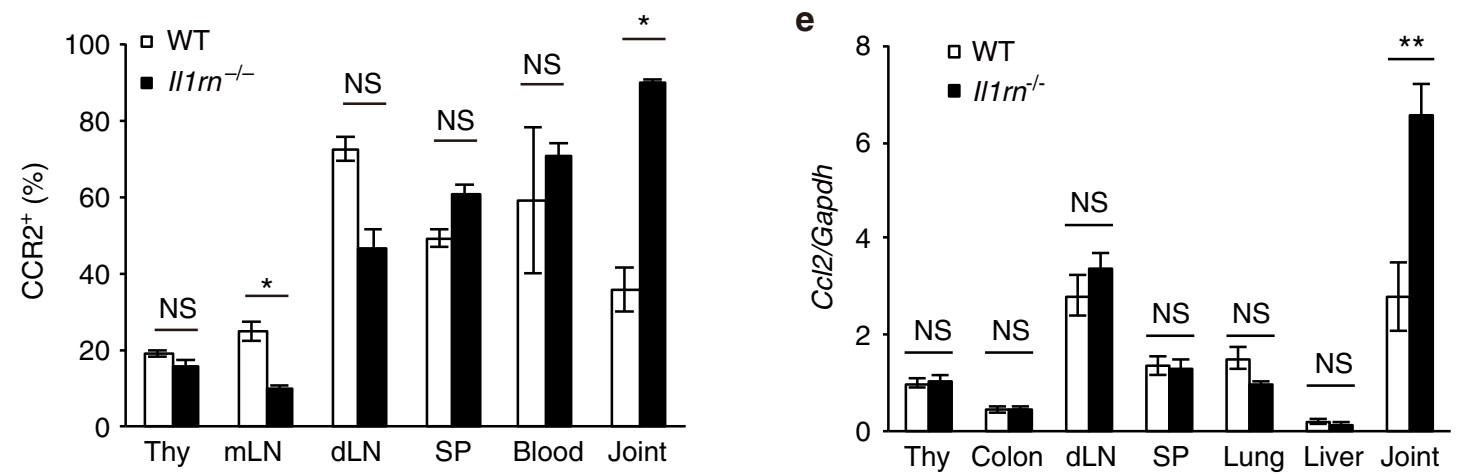

f
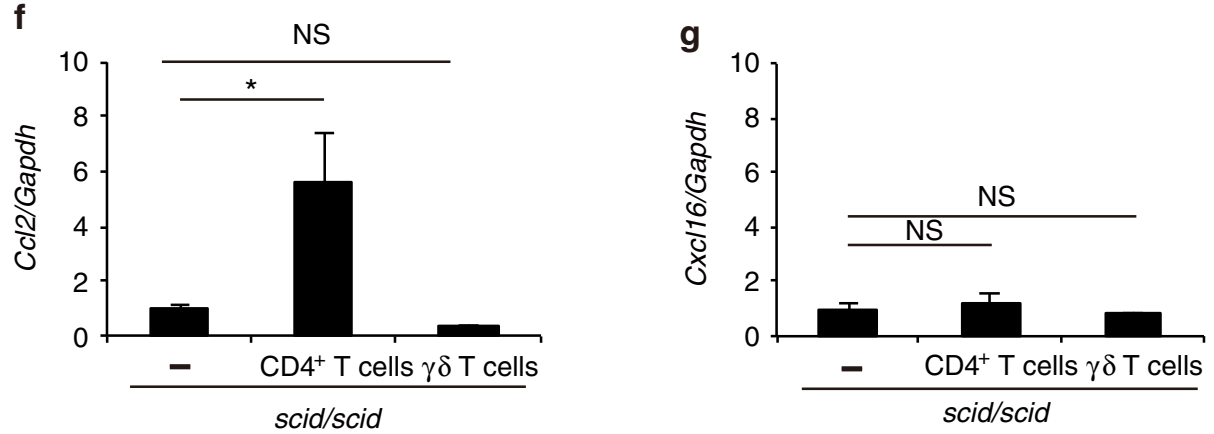
stimulation was higher in Il1 $\mathrm{rn}^{-1-} \gamma \delta \mathrm{T}$ cells than in WT $\gamma \delta$ $\mathrm{T}$ cells (Fig. 5f; Supplementary Fig. 6c). Ill $r^{-1-} \gamma \delta \mathrm{T}$ cells were less sensitive than WT $\gamma \delta$ T cells to inhibition of IL-1R expression by IL-1Ra, and the maximum levels of IL-1R expression induced by IL-1 $\beta$ and IL- 23 on WT $\gamma \delta$ T cells were lower than those on Illrn ${ }^{-l-} \gamma \delta \mathrm{T}$ cells (Fig. 5g). These results indicate that IL-1R expression is abnormally elevated in Ill $\mathrm{rn}^{-1}-\gamma \delta \mathrm{T}$ cells, resulting in higher IL-17 production in these cells (Fig. 5h). Thus, these results suggest that IL-1Ra is not merely an antagonist of IL$1 \mathrm{R}$ for the binding of IL- $1 \alpha$ and IL-1 $\beta$, but is also an important regulator of IL-1R expression on the cell surface.

${\mathrm{V} \gamma 6^{+}}^{+}$subset is the main IL-17 producer in $I l 1 \mathrm{rn}^{-/-}$joints. To identify the $\gamma \delta$ subset responsible for IL-17 production in $I l 1 \mathrm{rn}^{-1-}$ mouse joints, we examined the $\mathrm{V} \gamma$ subset in jointinfiltrating $\gamma \delta \mathrm{T}$ cells. Proportions of $\mathrm{V} \gamma$ subsets were analysed using $\mathrm{V} \gamma$ TCR-specific antibodies except for $\mathrm{V} \gamma 6$, because no anti- $V \gamma 6$ antibody was available. We found that $\gamma \delta \mathrm{T}$ cells in the joints consisted of only two major populations: ${\mathrm{V} \gamma 4^{+}}^{+}$and an 'other' population that was stained by none of antibodies against $\mathrm{V} \gamma 1, \mathrm{~V} \gamma 2, \mathrm{~V} \gamma 4, \mathrm{~V} \gamma 5$ or $\mathrm{V} \gamma 7$ TCR (Supplementary Fig. 7a). We assumed this 'other' $\mathrm{V} \gamma$ subset represented $\mathrm{V} \gamma 6^{+}$cells, because only $\mathrm{V} \gamma 6^{+}$cells are predicted to be unstained by all of these antibodies. $\gamma \delta$ T-cell subsets in LNs were heterogeneous, but only the $\mathrm{V} \gamma 4^{+}$and putative $\mathrm{V} \gamma 6^{+}$subsets were capable of producing IL-17 (Supplementary Fig. 7b).

Next, we analysed $\mathrm{V} \gamma$ subsets in $\gamma \delta 17$ cells using $I l 17^{g / g}$ $I l 1 \mathrm{rn}^{-1-}$ mice. An average of $80 \%$ of joint-infiltrating $\mathrm{GFP}^{+}$ $\gamma \delta \mathrm{T}$ cells were unstained by anti- $\mathrm{V} \gamma 4$ and anti- $\mathrm{V} \gamma 1 / 2$ antibodies (putative $\mathrm{V} \gamma 6^{+}$cells), and only $20 \%$ of the population was $\mathrm{V} \gamma 4^{+}$ (Fig. 6a,b). Furthermore, mean fluorescence intensity of GFP was significantly higher in ${\mathrm{V} \gamma 4^{-}}^{-}$cells than in $\mathrm{V} \gamma 4^{+}$cells (Fig. 6c). Furthermore, the putative $\mathrm{V} \gamma 6^{+}$cell population of IL-17 ${ }^{+} \gamma \delta \mathrm{T}$ cells $(63 \%)$ was larger than the $\mathrm{V} \gamma 4^{+}$cell population (37\%), as estimated by intracellular IL-17 staining (Supplementary Fig. 7c). The proportions of $\mathrm{V}_{4}{ }^{+}$cells in $\mathrm{IL}-17^{+}$and in GFP ${ }^{+} \gamma \delta$ $\mathrm{T}$ cells were slightly elevated following $\mathrm{P} / \mathrm{I}$ stimulation (Supplementary Fig. 7c,d), probably because GFP as well as IL-17 expression is elevated after P/I stimulation or cell activation ${ }^{23,36,37}$, and most ${\mathrm{V} \gamma 6^{+}}^{+}$cells were already activated in $I l 1 n^{-1-} \gamma \delta \mathrm{T}$ cells in vivo.

We also examined $\mathrm{V} \gamma$ subset composition by measuring $\mathrm{V} \gamma$ messenger RNA (mRNA) expression using reverse transcription (RT)-PCR. V $\gamma 6$ mRNA was preferentially expressed in FACSsorted $\mathrm{GFP}^{+} \gamma \delta \mathrm{T}$ cells in joints from Il17/g/g Ill $\mathrm{rn}^{-1-}$ mice, whereas other $\mathrm{V} \gamma$ mRNAs were also detected in $\mathrm{LN} \gamma \delta \mathrm{T}$ cells (Fig. 6d), consistent with the results of FACS analyses. V $\delta 1$ mRNA was exclusively detected in $\mathrm{GFP}^{+} \gamma \delta \mathrm{T}$ cells in joints
(Fig. 6e), suggesting that these cells are of the canonical $\mathrm{V} \gamma 6 / \mathrm{V} \delta 1$ $\gamma \delta$ T-cell subset ${ }^{38}$. Thus, $\mathrm{V} \gamma 6^{+} \gamma \delta \mathrm{T}$ cells are the major producers of IL-17 in joints of Illrn ${ }^{-1-}$ mice.

Ill $\mathrm{rn}^{-1-}{\mathrm{V} \gamma 6^{+}}^{+}$cells highly express IL-1R intrinsically. Because both ${\mathrm{V} \gamma 6^{+}}^{+}$and $\mathrm{V} \gamma 4^{+}$cells were present in joints with high levels of CCR2 expression on the surface (Fig. 7a), we asked why IL-17 was preferentially produced by $\mathrm{V} \gamma 6^{+}$cells in Ill $\mathrm{rn}^{-1-}$ mouse joints. IL-1R expression on $\gamma \delta \mathrm{T}$ cells was greatly elevated in both LNs and joints of $\mathrm{Ill} \mathrm{m}^{-1-}$ mice (Fig. 7b), and most GFP ${ }^{+} \gamma \delta$ T cells in $I l 117^{g / g}$ Ill $^{-1} n^{-1}$ mouse joints were IL-1R ${ }^{+}$(Fig. 7c). This IL-1 $\mathrm{R}^{+}$population was mostly $\mathrm{V} \gamma 6^{+}$(Fig. 7d). The mean fluorescence intensity of IL-1R was also significantly higher in ${\mathrm{V} \gamma 6^{+}}^{+}$cells than in $\mathrm{V} \gamma 4^{+}$cells (Fig. 7e). This elevated IL-1R expression was already present in newborn thymic $\gamma \delta$ T cells from Illirn ${ }^{-1}$ mice (Fig. 7f), and was detected on $\mathrm{V} \gamma 6^{+}\left(\mathrm{V} \gamma 4^{-}, \mathrm{V} \gamma 1^{\prime} 2^{-}, \mathrm{V} \gamma 5^{-}\right.$and $\left.\mathrm{V} \gamma 7^{-}\right)$cells (Fig. 7g). Notably, IL-1R expression on $\gamma \delta \mathrm{T}$ cells in newborn thymus correlated with CCR2 expression (Fig. 7h). IL-1 $\beta$ mRNA expression was observed even in joints of WT mice, and was greatly elevated in joints of $I l l \mathrm{rn}^{-1}$ - mice (Fig. 7i). IL-23 mRNA expression in joints was also significantly higher in Ill $\mathrm{rn}^{-1-}$ mice than in WT mice (Fig. 7j). These observations suggest that joint-infiltrating CCR2 ${ }^{+} \mathrm{V} \gamma 6^{+} I l 1 r n^{-1-} \gamma \delta \mathrm{T}$ cells, which intrinsically express high levels of IL-1R, preferentially produce IL-17 in response to IL-1 $\beta$ and IL-23, resulting in development of arthritis.

\section{Discussion}

Here we showed that both $\mathrm{CD} 4^{+} \mathrm{T}$ cells and $\gamma \delta 17$ cells are important for development of arthritis in $I l 1 \mathrm{rn}^{-1-}$ mice, because antibody-mediated depletion of either $\gamma \delta \mathrm{T}$ or $\mathrm{CD} 4{ }^{+} \mathrm{T}$ cells suppressed the development of arthritis. Furthermore, upon adoptive transfer, only a mixture of $\gamma \delta \mathrm{T}$ and $\mathrm{CD} 4{ }^{+} \mathrm{T}$ cells induced arthritis in scid/scid mice. $\gamma \delta 17$ cells localized in joints of scid/scid mice when $\gamma \delta \mathrm{T}$ cells were transferred along with $\mathrm{CD} 4{ }^{+} \mathrm{T}$ cells, whereas $\gamma \delta \mathrm{T}$ cells were not detected in joints when $\gamma \delta \mathrm{T}$ cells were transferred alone. These observations suggest that $\gamma \delta \mathrm{T}$ cells alone cannot distribute into joints, and $\mathrm{CD} 4{ }^{+} \mathrm{T}$ cells are required for the localization of $\gamma \delta \mathrm{T}$ cells.

Anti- $\gamma \delta$ TCR mAb injection significantly suppressed not only the incidence of arthritis but also the histological severity score, indicating that $\gamma \delta$ T cells are involved in development of arthritis. It was recently reported that treatment with anti- $\gamma \delta \mathrm{TCR} \mathrm{mAb}$ results in internalization of $\gamma \delta$ TCR rather than $\gamma \delta$ T-cell depletion ${ }^{39}$. In our hands, however, the $\gamma \delta$ T-cell population was greatly diminished by treatment with this antibody, indicating that the $\gamma \delta 17$ population is actually depleted by this antibody.

Figure 3 | CCR2 ${ }^{+} \gamma \boldsymbol{\delta} \mathbf{1 7}$ cells predominantly accumulate in II1rn ${ }^{-/}$mouse joints. (a) Expression of chemokine receptors and GFP on joint-infiltrating cells from WT $\left(n=3\right.$, pool of two mice each), $111 r^{-/}-(n=3)$ and $11179 / 9 / 11 r^{-/}-(n=3)$ mice at 16 weeks of age. Numbers represent percentages in $\mathrm{CD} \varepsilon^{+} \gamma \delta \mathrm{TCR}^{+}$cells. Numbers in parentheses represent percentages in GFP + CD3 $\varepsilon^{+} \gamma \delta \mathrm{TCR}+$ cells. (b) Quantitative PCR (qPCR) analysis of the transcripts of CCL2 (Cc/2), CXCL16 (Cxcl16), CCL20 (CCl20), CCL5 (CCI5) and CXCL12 (CxCl12) in joints of WT $(n=4)$ or I/1rn ${ }^{-/-}(n=4)$ mice. Values are shown relative to those in WT mice. ${ }^{\star} P<0.05$; ${ }^{\star \star} P<0.01$; NS, not significant (versus WT mice) (unpaired Student's t-test). (c) Flow cytometry of the jointinfiltrating $\gamma \delta$ T cells from WT, arthritic $\| 17 r^{-/}$and non-arthritic $\left\|17 a^{-/}-\right\| 17 r^{-/}-$mice. Numbers represent percentages in CD3 $\varepsilon^{+}$cells. Numbers in parentheses represent percentages in $\mathrm{CD}_{2} \varepsilon^{+} \gamma \delta \mathrm{TCR}{ }^{+}$cells. (d) Contents of CCR2 ${ }^{+}$cells in $\mathrm{CD} 3 \varepsilon^{+} \gamma \delta \mathrm{TCR}^{+}$cells in the thymus (Thy), mesenteric LNs $(\mathrm{mLN})$, draining LNs $(\mathrm{dLN})$, spleens (SP), blood and joints of WT $(n=3)$ and $117 r^{-1}{ }^{-}(n=3)$ mice at the age of 14 weeks. ${ }^{\star} P<0.05 ;$ NS $($ versus WT mice) (unpaired Student's $t$-test). (e) Levels of CCL2 mRNA in whole tissue were measured by qPCR in various tissues from WT $(n=5)$ and $I / 1 r n-/-(n=5)$ mice at the age of 8 weeks. Values are shown relative to those in WT mouse thymus total RNA. ${ }^{\star \star} P<0.01$; NS (versus WT mice) (unpaired Student's $t$-test). (f,g) qPCR analysis of mRNA for CCL2 (f) and CXCL16 (g) in joints of scid/scid mice after 24 weeks of transfer of CD4 ${ }^{+}$T cells $(n=4)$ or $\gamma \delta$ T cells $(n=3)$, or age-matched scid/scid mice $(n=3)$. Values are shown relative to those in control scid/scid mice. ${ }^{\star} P<0.05$; NS versus control scid/scid mice (unpaired Student's t-test). mRNA expression was normalized to that of Gapdh (b,e-g). All data except a and $\mathbf{c}$ show mean \pm s.e.m. Data are representative of two $(\mathbf{c}-\mathbf{g})$ or $>3(\mathbf{a}, \mathbf{b})$ independent experiments. 


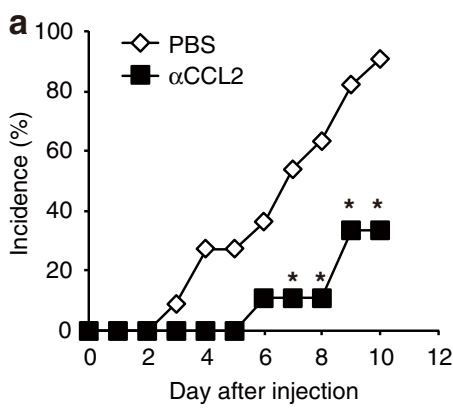

b Gated on $\mathrm{CD}^{+}$cells

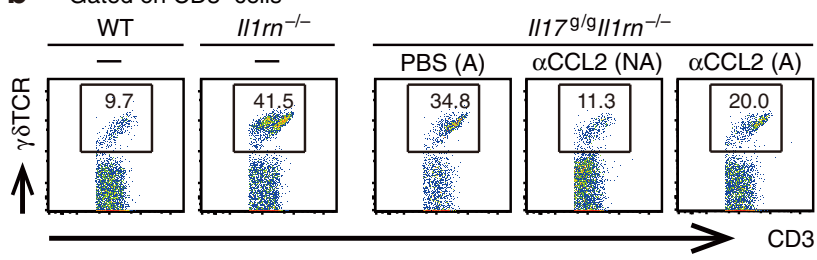

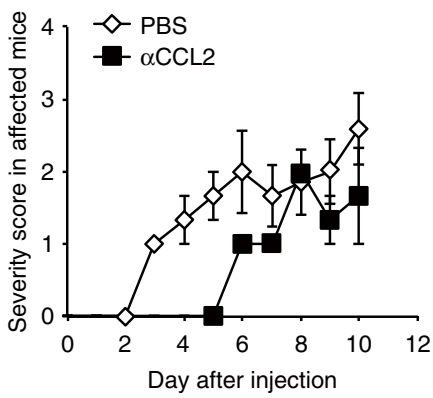

C

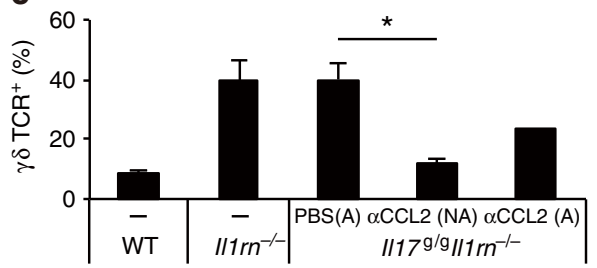

d Gated on $\gamma \delta \mathrm{TCR}^{+}$cells
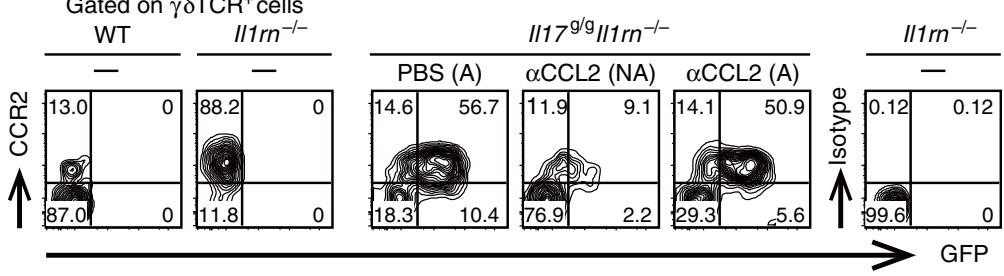

e
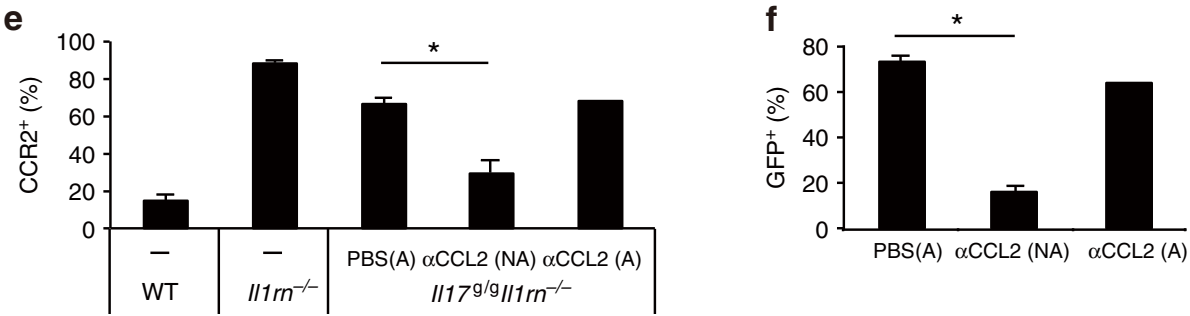

g Gated on $\mathrm{GFP}^{+} \gamma \delta \mathrm{TCR}^{+}$cells

h

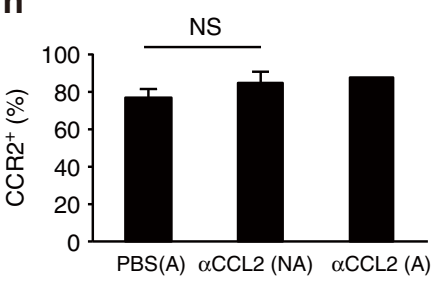

j

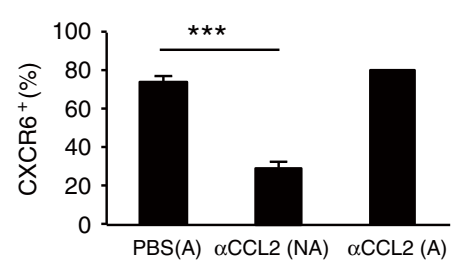

Figure 4 | CCL2 is essential for $\boldsymbol{\gamma} \boldsymbol{\delta}$ T-cell infiltration into joints and arthritis development. (a) Incidence (left) and severity scores of arthritis in affected mice (right) in $1 / 179 / 9 / 17 r^{-1}-$ mice after anti-CCL2 mAb treatment. Non-arthritic $/ 177^{g} / \mathrm{g} / 11 \mathrm{rn}-/-$ mice at the age of 21 days were injected with anti-CCL2 $\operatorname{mAb}(\boldsymbol{\square}, n=9)$ or $\mathrm{PBS}(\diamond, n=11)$ every 3 days (ages of $21,24,27$ and 30 days). ${ }^{\star} P<0.05$ versus treatment with PBS, assessed by the $\chi^{2}$-test. Data represent a pool of two independent experiments. (b-j) Flow cytometry of joint-infiltrating cells from $/ 1179 / g / 11 \mathrm{rn}^{-/}-$mice 11 days after the first injection. Cells were collected from PBS-treated arthritic (A) mice $(n=5)$ and anti-CCL2 mAb-treated non-arthritic $(N A)(n=3)$ or arthritic $($ A) $(n=2)$ mice. Agematched and non-treated WT $(n=3)$ and arthritic $117 n^{-1-}(n=3)$ mice were used as controls. Numbers refer to percentage in CD3 $\varepsilon^{+}$cells $(\mathbf{b})$, in $\mathrm{CD}_{\varepsilon} \varepsilon^{+} \gamma \delta \mathrm{TCR}{ }^{+}$cells $(\mathbf{d})$ or in $\mathrm{GFP}+\mathrm{CD}_{\varepsilon}{ }^{+} \gamma \delta \mathrm{TCR}{ }^{+}$cells $(\mathbf{g}, \mathbf{i})$. The average proportions of $\gamma \delta \mathrm{T}$ cells in $\mathrm{CD} 3 \varepsilon^{+}$cells $(\mathbf{c}), \mathrm{CCR} 2{ }^{+}(\mathbf{e})$ or $\mathrm{GFP}+(\mathbf{f})$ cells among $\gamma \delta \mathrm{TCR}^{+}$cells, or CCR2 ${ }^{+}(\mathbf{h})$ or $\mathrm{CXCR6}^{+}(\mathbf{j})$ cells among GFP ${ }^{+} \gamma \delta \mathrm{TCR}{ }^{+}$cells, are shown. ${ }^{\star} P<0.05 ;{ }^{* \star \star} P<0.001$; NS, not significant (versus I/179/ $9 / 17 r^{-/}-$mice treated with PBS) (unpaired Student's $t$-test). Data show mean \pm s.e.m. Data $(\mathbf{b}-\mathbf{j})$ are representative of two independent experiments. 


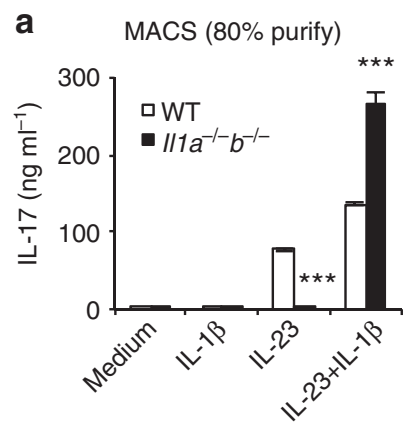

C

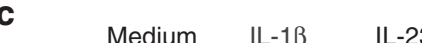

WT

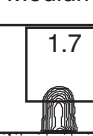

$1 / 1 r 1^{-1-}$
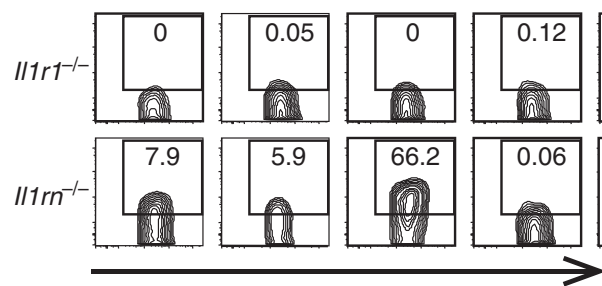

e

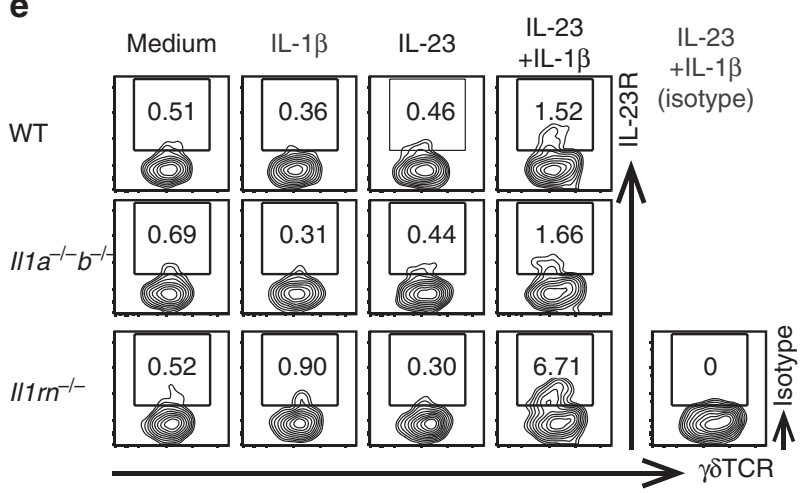

d

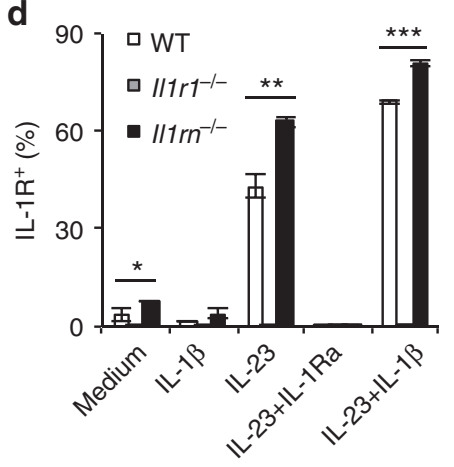

f

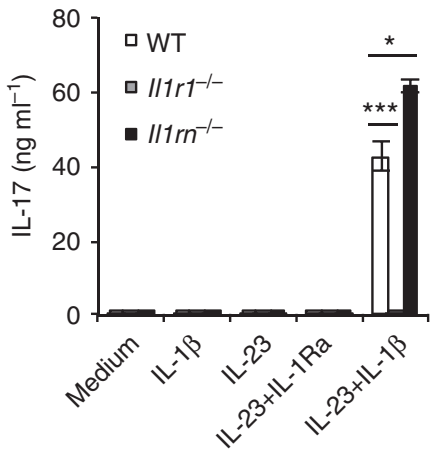

g

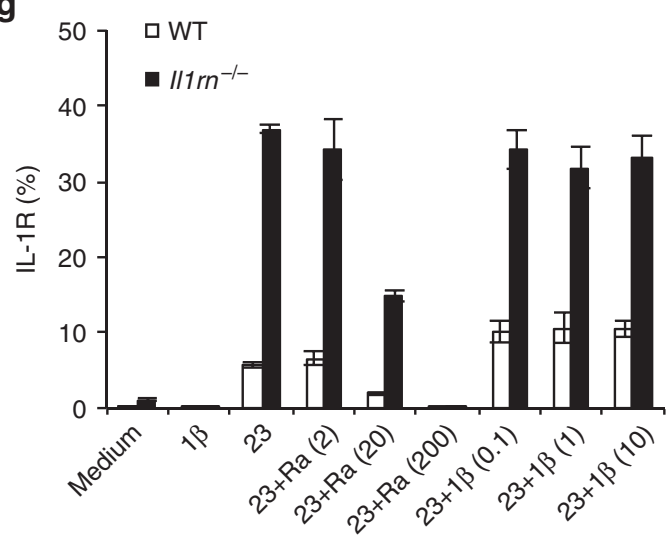

h

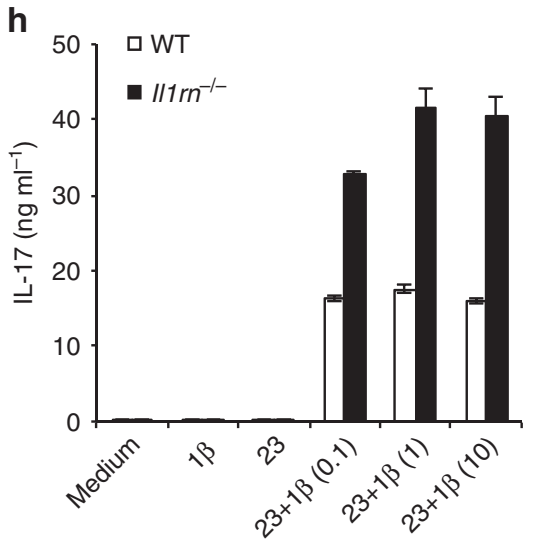

Figure 5 | IL-23 induces expression of IL-1R on the surface of $\gamma \boldsymbol{\delta} \mathbf{T}$ cells, whereas IL-1Ra suppresses its expression. (a,b) Concentrations of IL-17 in culture supernatants of magnetic-activated cell sorting (MACS)-purified (about $80 \%$ ) (a) or FACS-purified ( $>99 \%$ pure) (b) splenic $\gamma \delta$ T cells from pools of 16 WT mice $(\mathbf{a}, \mathbf{b})$ or $16 / 17 a^{-/-b^{-/}-}$mice (b) stimulated for 3 days with medium only, IL-1 $\beta$, IL-23 or IL-23 plus IL-1 $\beta$, without $\gamma \delta$ TCR stimulation. IL-17 was detected by enzyme-linked immunosorbent assay (ELISA). ${ }^{\star \star \star} P<0.001$ versus WT mice (a); ${ }^{\star \star \star} P<0.001$ versus medium only (b) (unpaired Student's $t$-test). (c-h) FACS-purified $\gamma \delta$ T cells from pooled spleens of WT, $\left\|171^{-/-},\right\| 1 a^{-/-} b^{-/-}$or $\| 11 r^{-/-}$mice (11-16 mice each) were stimulated for 3 days with medium only, IL-1 $\beta$, IL-23, IL-23 plus IL-1 $\beta$ or IL-23 plus IL-Ra. Flow cytometry of $\gamma \delta$ T cells stained for surface IL-1R (c) and IL-23R (e) are shown. Quantification of IL-1R ${ }^{+} \gamma \delta$ T cells is indicated in $\mathbf{d}$ and $\mathbf{g}$. Concentrations of IL-17 in culture supernatants were determined by ELISA (f,h). ${ }^{\star} P<0.05$; ${ }^{\star \star} P<0.01$; ${ }^{\star \star \star} P<0.001$ (versus WT mice) (unpaired Student's t-test). Numbers in parentheses indicate the concentration of cytokines (ng ml ${ }^{-1}$ ). Representative data $(\mathbf{c}, \mathbf{e})$ and mean \pm s.e.m. $(\mathbf{a}, \mathbf{b}, \mathbf{d}, \mathbf{f}, \mathbf{g}, \mathbf{h})$ of triplicate cultures are shown. All data are representative of two or three independent experiments. 
a No stimulation
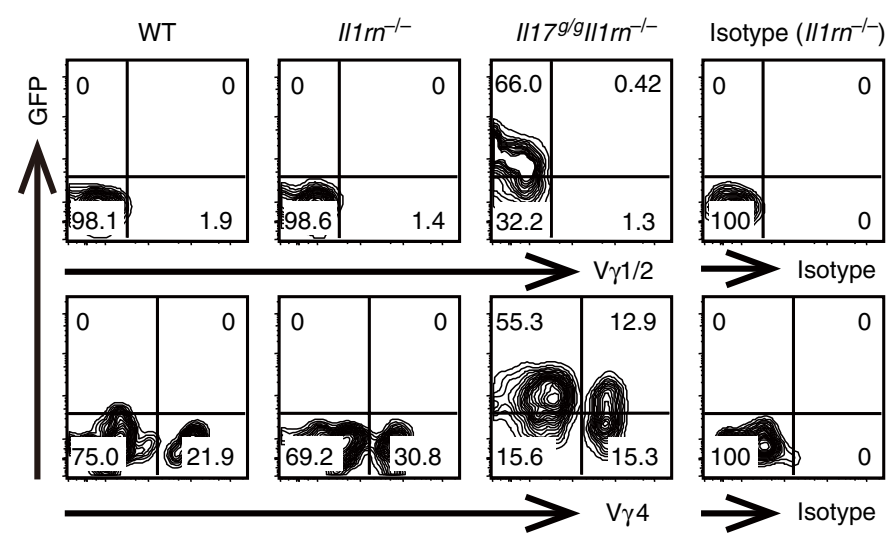

b

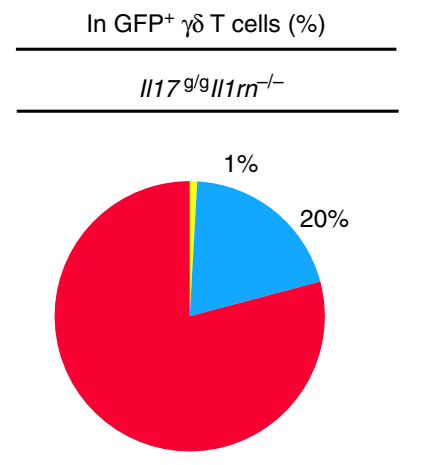

$79 \%$

\section{d}

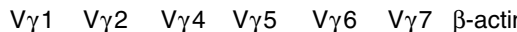

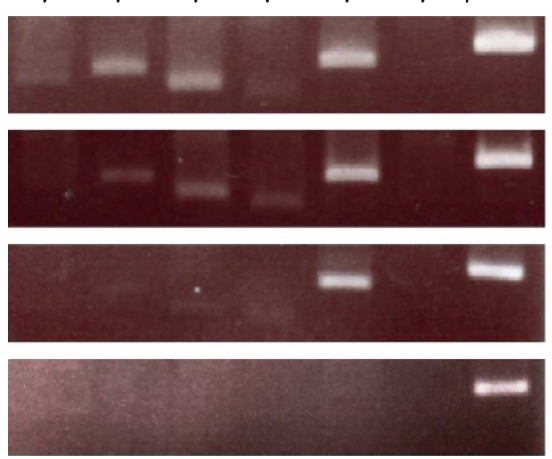

$\mathrm{V} \gamma 1 / 2^{+}$

$\mathrm{V} \gamma 4^{+}$

$\mathrm{V} \gamma 1 / 2^{-} \vee \gamma 4^{-}$ $\left(=\mathrm{V} \gamma 6^{+}\right)$
Gated on $\gamma \delta \mathrm{T}$ cells

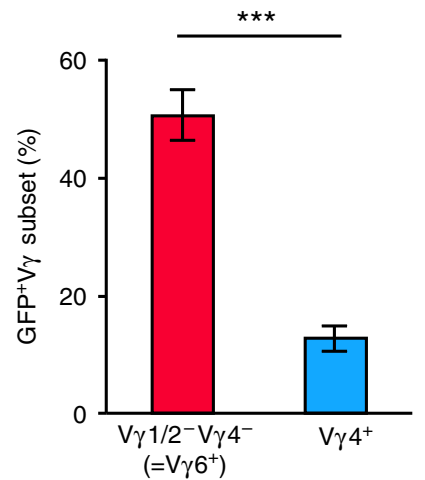

C
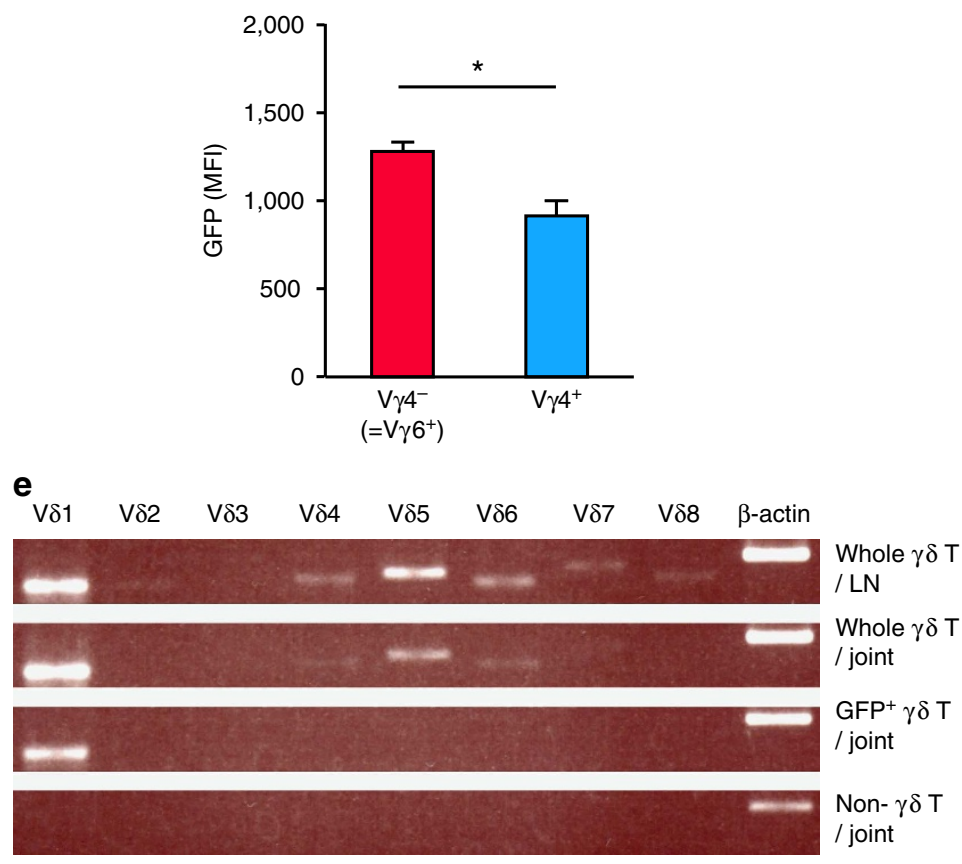

Figure 6 | The $\mathbf{V} \gamma \mathbf{6}^{+} \gamma \boldsymbol{\delta}$ T-cell subset is the major source of IL-17 in II1rn ${ }^{-/-}$mouse joints. (a-c) GFP expression in joint-infiltrating $\gamma \delta$ T cells from WT,

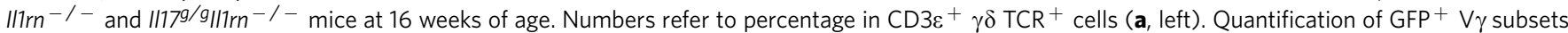
in $\mathrm{CD}_{\varepsilon} \varepsilon^{+} \gamma \delta \mathrm{TCR}^{+}$cells is shown (a, right). Numbers in the pie chart show the percentages of the indicated $\mathrm{V} \gamma$ subset among GFP ${ }^{+} \gamma \delta \mathrm{TCR}^{+} \mathrm{CD} \varepsilon^{+}$ cells, and represent the average of three mice (b). Mean fluorescence intensity of GFP in $V \gamma 6^{+}\left(V \gamma 4^{-}\right)$or $V \gamma 4^{+}$cells is shown in c. ${ }^{\star} P<0.05$, ${ }^{\star \star \star} P<0.001$ (versus $\vee \gamma 4^{+}$cells) (unpaired Student's $t$-test). Data show the mean \pm s.e.m. of three mice. (d,e) $\vee \gamma(\mathbf{d})$ and $\vee \delta(\mathbf{e})$ gene expression in $\gamma \delta T$ cells. CD $3 \varepsilon^{+} \gamma \delta \mathrm{TCR}^{+}$(whole $\gamma \delta \mathrm{T}$ ) cells from LNs (first row) or from joints (second row) of $1 / 1 \mathrm{rn}^{-/}-$mice and GFP ${ }^{+} \mathrm{CD}^{+} \varepsilon^{+} \gamma \delta \mathrm{TCR}+(\mathrm{GFP}+\gamma \delta \mathrm{T}$ ) (third row) or $\mathrm{CD} \varepsilon^{+} \gamma \delta \mathrm{TCR}^{-}$(non- $\gamma \delta \mathrm{T}$ ) (fourth row) cells from joints of $1 / 17 \mathrm{~g} / \mathrm{g} / 11 \mathrm{rn}^{-/}$- mice, were sorted on a FACSAria, and $\mathrm{V} \gamma$ and $\mathrm{V} \delta$ gene expression was analysed by RT-PCR.

Importantly, the $\gamma \delta 17$ population was significantly reduced without a compensatory increase in $\mathrm{IL}-17^{+}$cells in the $\gamma \delta$ $\mathrm{TCR}^{-}$population, suggesting that the reduction of $\gamma \delta 17$ cells was not the result of replacement of $\gamma \delta 17$ cells by hypothetical 'invisible $\gamma \delta$ T cells $^{\prime 39}$. A reduction in IL-17 production following anti- $\gamma \delta$ TCR $\mathrm{mAb}$ treatment was also reported by another group ${ }^{40}$. Although we examined the effect of $\gamma \delta$ T-cell deficiency using $\mathrm{Tcrd}^{-1-}$ mice, we could not find any effect of this gene mutation on the development of arthritis. Interestingly, we found IL-17-producing $\mathrm{CD} 4^{-} \mathrm{CD} 8{ }^{-} \gamma \delta \mathrm{TCR}^{-} \mathrm{T}$ cells were increased in the joints of Tcrd ${ }^{-1-}$ Illrn ${ }^{-1-}$ mice, suggesting that these cells may substitute for the deficiency of $\gamma \delta \mathrm{T}$ cells to produce IL-17. We are now further characterizing these cells.

In $I l 17^{g / g} / l 1 \mathrm{rn}^{-1-}$ mice, most of the joint-infiltrating $\gamma \delta 17$ cells expressed CCR2, in association with elevated expression of CCL2 in the joints. Antibody-mediated blockade of CCL2 in 
$I l 17^{g / g}{ }^{I l 1 r^{-I}}{ }^{-}$mice reduced infiltration of $\mathrm{CCR}^{+} \mathrm{GFP}^{+} \gamma \delta$ $\mathrm{T}$ cells in joints and suppressed the development of arthritis, suggesting that $\mathrm{CCR} 2{ }^{+} \gamma \delta 17$ cell accumulation in the joints, which is critical for the development of arthritis, is mediated by the CCL2-CCR2 interaction. The CCL2-CCR2 axis-mediated $\gamma \delta$ $\mathrm{T}$-cell migration has also been reported as a protection mechanism against tumours ${ }^{41}$. Regarding CCR2 expression, a subset of $\gamma \delta \mathrm{T}$ cells acquires effector functions and expresses IL-17 during intrathymic development ${ }^{15,16}$, and these thymic $\gamma \delta 17$ subsets already express some chemokine receptors such as CCR2, CCR6 and CXCR6 (refs 17,18). In contrast to $\gamma \delta 17$ cells in Il1 $r^{-1}$ mice, pathogenic Th17 cells expressing CCR6 are a

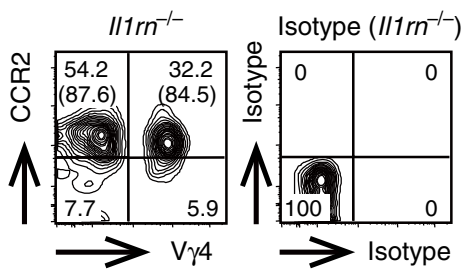

b $_{\text {LN }}$

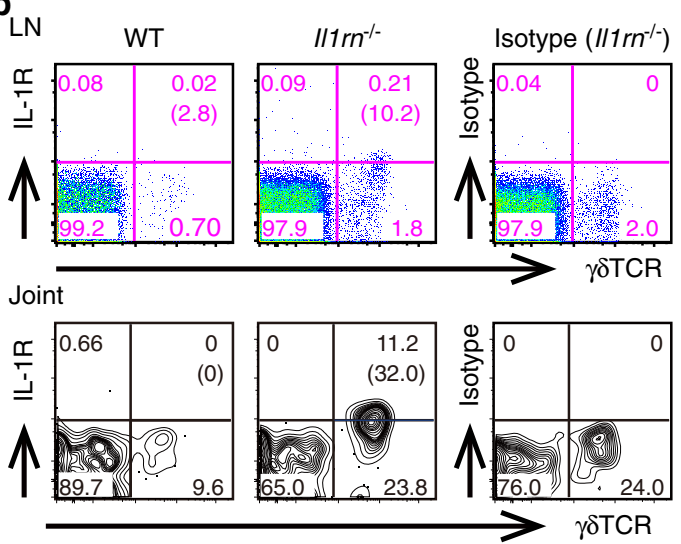

C

Gated on $\gamma \delta$ T cells

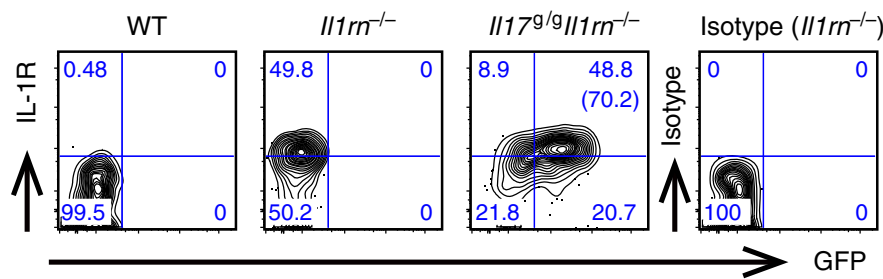

d

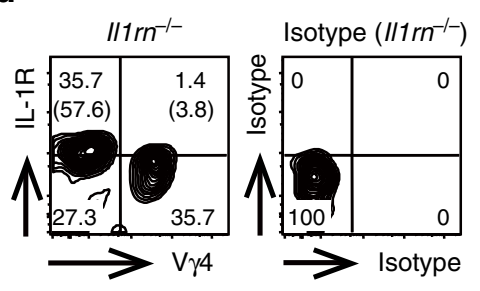

In $\mathrm{V} \gamma 4^{-} / \mathrm{V} \gamma 4^{+}$cells

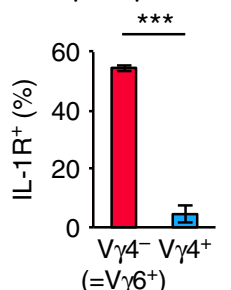

e

In $\mathrm{V} \gamma 4^{-} / \mathrm{V} \gamma 4^{+}$cells
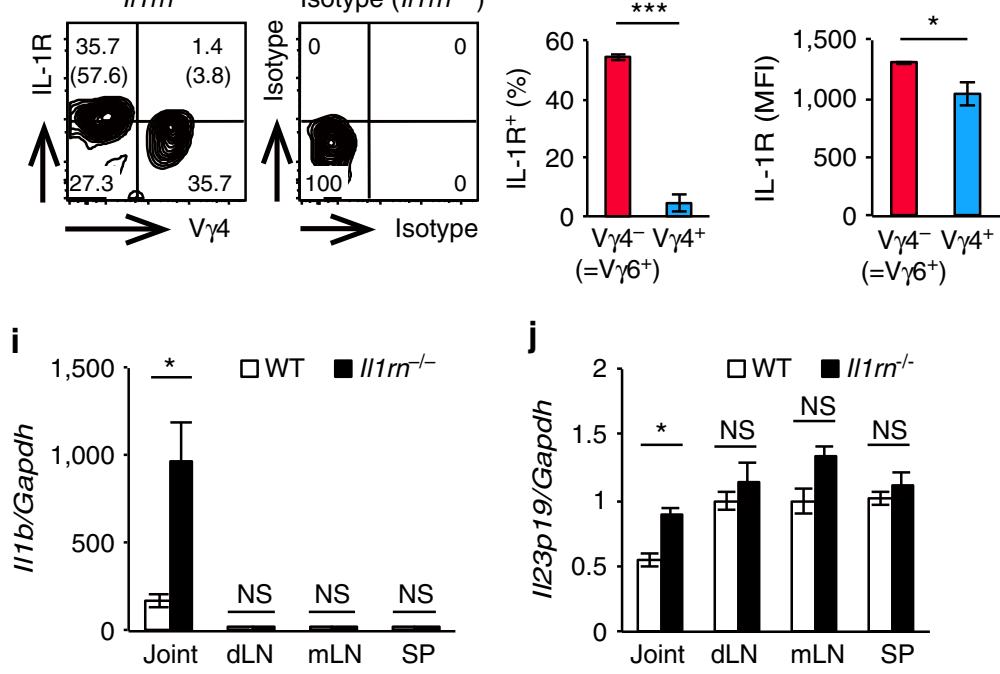

$\ln \mathrm{V} \gamma 4^{-} / \mathrm{V} \gamma 4^{+}$cells
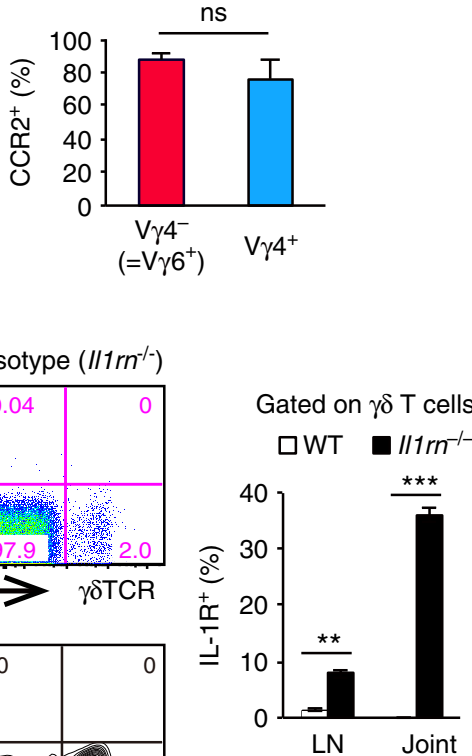

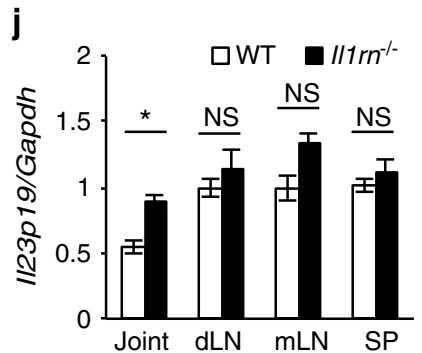

f

Gated on $\mathrm{CD}^{+} \mathrm{T}$ cells/Newborn Thy

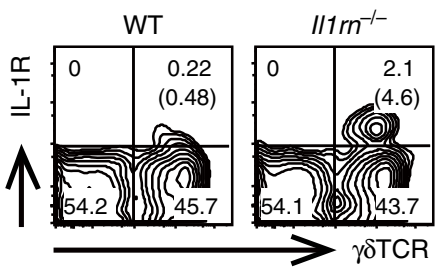

g

Gated on $\gamma \delta$ T cells/Newborn Thy

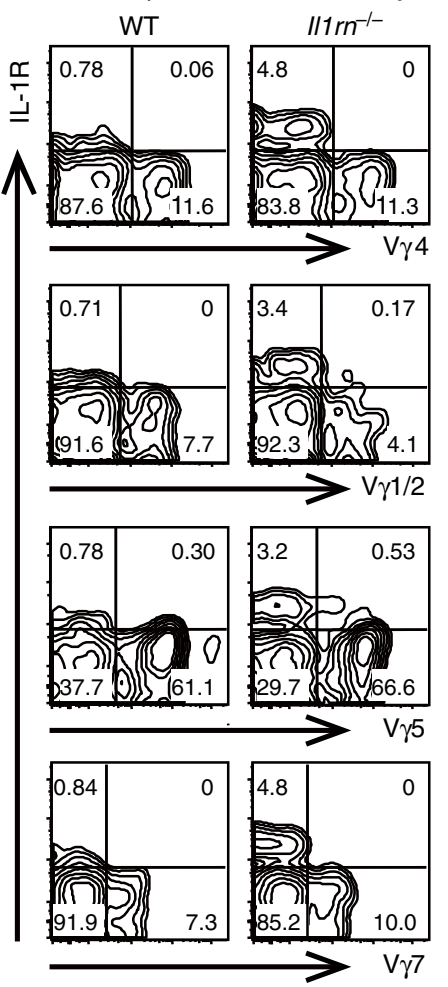

h

Gated on $\mathrm{CD}^{+} \mathrm{T}$ cells/Newborn Thy

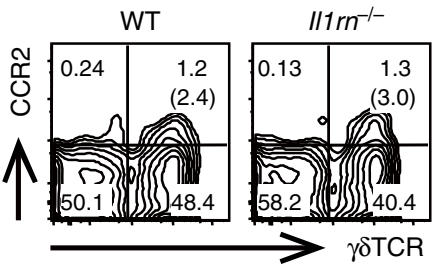

Gated on $\gamma \delta$ T cells/Newborn Thy

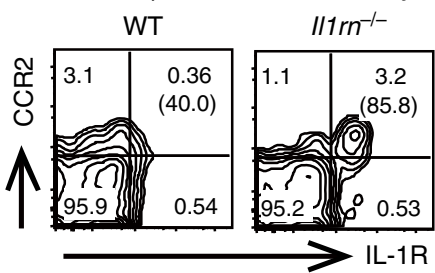


recruited to inflammatory sites, such as joints of SKG mice ${ }^{42}$ and the central nervous system of an experimental autoimmune encephalomyelitis model ${ }^{43,44}$, via the CCR6-CCL20 interaction. Because we did not observe a significant increase in CCL20 expression in joints of $I l 1 \mathrm{rn}^{-1-}$ mice relative to WT mice, the CCR6-CCL20 axis may not be important for the $\gamma \delta 17$ cell migration into joints, even though $>50 \%$ of joint-infiltrating $\mathrm{GFP}^{+} \gamma \delta \mathrm{T}$ cells in $1 l 17^{g / g} g_{1 l 1} \mathrm{rn}^{-1-}$ mice also expressed CCR6. CXCR6 was also expressed on joint-infiltrating $\gamma \delta 17$ cells in $I l 17^{g / g} / l 1 r^{-1-}$ mice. However, because this chemokine receptor was not expressed on joint-infiltrating $\gamma \delta \mathrm{T}$ cells in nonarthritic Il17a-1- Il1rn ${ }^{-1-}$ mice, CXCR6 may not be involved in recruitment of $\gamma \delta \mathrm{T}$ cells, at least under non-inflammatory conditions.

Importantly, Illrn ${ }^{-1-} \mathrm{CD} 4{ }^{+} \mathrm{T}$-cell transfer induced CCL2 expression in joints of recipient scid/scid mice, suggesting that $\mathrm{CD} 4{ }^{+} \mathrm{T}$ cells directed the migration of CCR2 ${ }^{+} \gamma \delta \mathrm{T}$ cells. We rarely detected Th17 cells in the inflamed joints, indicating that IL-17 production from $\mathrm{CD}_{4}{ }^{+} \mathrm{T}$ cells is not required for pathogenesis in $\mathrm{Illrn}^{-1-}$ mice, at least for induction of local inflammation. Therefore, our results show that $\mathrm{CD} 4{ }^{+} \mathrm{T}$ cells direct the tissue specificity of inflammation, and $\gamma \delta 17$ cell-derived IL-17 elicits local inflammation and arthritis in $111 \mathrm{rn}^{-/}$mice. Although the importance of $\gamma \delta 17$ cells in the development of arthritis in the collagen-induced arthritis model was already suggested by Ito et al. ${ }^{13}$, the mechanism how these $\gamma \delta \mathrm{T}$ cells are distributed to joints has not been elucidated. In this report, we first clarified the mechanism how $\gamma \delta$ T cells are recruited to the inflammatory site. Actually, when $\gamma \delta \mathrm{T}$ cells alone were transferred to scid/scid mice, development of inflammation was observed in other organs, such as the colon and dermis, suggesting the importance of $\mathrm{CD}_{4}^{+} \mathrm{T}$ cells for the tissuespecific distribution of $\gamma \delta$ T cells. We showed previously that $\mathrm{T}$ cells from $I l 1 n^{-1-}$ mice are hyper-reactive due to the overexpression of CD40L and OX40 on the cell surface, and consequently lose tolerance against self-antigens ${ }^{32,33}$.

A combination of IL-1 $\beta$ and IL-23, but not IL-1 $\beta$ or IL-23 alone, induces IL-17 in $\gamma \delta \mathrm{T}$ cells without TCR engagement ${ }^{11,13,20,35}$. In this report, we showed that IL-23 is required for the induction of IL-1R on $\gamma \delta$ T cells, and IL- $1 \beta$ is essential for the induction of IL-17. However, IL-1 $\beta$ alone could not induce IL-17 production in Il1 $\mathrm{rn}^{-/}-\gamma \delta \mathrm{T}$ cells, even though these cells expressed IL-1R, consistent with a report that IL-1 $\beta$ alone does not induce IL-17 in peritoneum- and lung-derived $\gamma \delta \mathrm{T}$ cells expressing high levels of IL- $1 \mathrm{R}^{20}$. These observations suggest that IL-23 plays roles, other than upregulating IL-1R, in the induction of IL-17 expression in $\gamma \delta \mathrm{T}$ cells. In this context, expression of
IL-17 signature transcription factors such as Rorc, Rora, Nfkbz and Batf was increased by IL-1 $\beta$ and IL-23 together.

Moreover, IL-23-induced IL-1R expression on $\gamma \delta$ T cells was suppressed by exogenous IL-1Ra, suggesting that IL-1Ra not only antagonizes IL- $1 \alpha$ and IL- $1 \beta$ for IL-1R binding, but also regulates cell-surface expression of IL-1R. Consistent with this, IL-1R

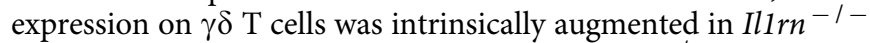
mice, making IL-17 production by these Il1rn-l- $\gamma \delta \mathrm{T}$ cells hyper-sensitive to the action of IL-1 $\beta$ and IL-23. Ill rn ${ }^{-/-} \gamma \delta$ $\mathrm{T}$ cells induced arthritis upon transfer into scid/scid mice. Because IL-1R expression levels induced by IL-1 $\beta$ and IL-23 were much higher on Illrn ${ }^{-1-} \gamma \delta \mathrm{T}$ cells than on WT $\gamma \delta \mathrm{T}$ cells, endogenous low levels of IL-1Ra in the recipients could not suppress IL-1R expression on Il1rn ${ }^{-1-} \gamma \delta \mathrm{T}$ cells. Thus, the strict control of IL-1R expression by IL-1Ra is important for regulation of IL-17 production in $\gamma \delta$ T cells.

Children with homozygous point mutations or deletions of the $I L 1 R N$ gene develop life-threatening severe inflammatory diseases with prominent involvement of bone and skin after birth ${ }^{45,46}$. The population of IL-17-producing cells is markedly elevated in inflamed skin, and a large amount of IL-1 $\beta$ is produced in mononuclear cells, as in Ill $\mathrm{rn}^{-1-}$ mice $^{45,46}$. Although the pathogenic roles of IL-17 in local inflammation in these patients remain unknown, $\gamma \delta \mathrm{T}$ cells may be involved in the inflammation. Our observation that exogenous IL-Ra suppresses IL-1R expression on $\gamma \delta$ T cells may partly explain why treatment with the recombinant IL-1Ra anakinra completely resolves symptoms in these affected children ${ }^{45,46}$.

Using $I l 17^{g / g}$ mice, we showed that IL-17 was preferentially produced in ${\mathrm{V} \gamma 6^{+}}_{\gamma} \delta \mathrm{T}$ cells of Ill $\mathrm{rn}^{-1-}$ mouse joints, although both CCR2 ${ }^{+} \mathrm{V} \gamma 6^{+}$cells and CCR2 ${ }^{+} \mathrm{V} \gamma 4^{+}$cells were localized in the joints. These results suggest that IL-17 production capacity differs in these two $\gamma \delta$ T-cell subsets. We found that IL-1R expression in joints is much higher on $\mathrm{V} \gamma 6^{+}$cells than on $\mathrm{V} \gamma 4^{+}$ cells, explaining why IL-17 is induced preferentially in $\mathrm{V} \gamma 6^{+}$cells in Il1 $\mathrm{rn}^{-1-}$ mice. This elevated IL-1R expression was observed even in newborn thymus. Notably in this regard, different transcription factors are required for the development of $\mathrm{V} \gamma 6^{+}$and $\mathrm{V} \gamma 4^{+}$cell subset ${ }^{24}$, and $\mathrm{V} \gamma 6^{+}$cells acquire the innate capacity to produce IL-17 in the embryonic thymus ${ }^{47}$. Therefore, during embryonic development, the level of IL-1R is probably intrinsically higher in $\mathrm{V} \gamma 6^{+} \gamma \delta \mathrm{T}$ cells than in $\mathrm{V} \gamma 4^{+}$cells.

$\mathrm{V} \gamma 6^{+} \gamma \delta 17$ cells are thought to be a tissue-resident, long-lived, self-renewing population ${ }^{47}$. Although our CCL2 inhibition and transfer experiments suggested that $\mathrm{LN} \mathrm{V} \gamma 6^{+} \gamma \delta \mathrm{T}$ cells capable of producing IL-17 were recruited to joints (where they induced

Figure 7 | IL-17-producing II1rn ${ }^{-/-} \mathbf{V}_{\gamma \boldsymbol{6}^{+}} \boldsymbol{\gamma} \boldsymbol{\delta} \mathbf{T}$ cells intrinsically express high levels of IL-1R. (a) Flow cytometry of joint-infiltrating cells from I/1rn ${ }^{-/-}$ mice $(n=3)$ for the expression of CCR2 and $V \gamma 4$. Numbers refer to percentage in CD3 $\varepsilon^{+} \gamma \delta$ TCR ${ }^{+}$cells. Numbers in parentheses represent percentage in $\mathrm{V} \gamma 6^{+}\left(\mathrm{V} \gamma 4^{-}\right)$or $\mathrm{V} \gamma 4^{+}$cells (left). Quantification of CCR2 ${ }^{+}$cells in $\mathrm{V} \gamma 6^{+}\left(\mathrm{V} \gamma 4^{-}\right)$or $\mathrm{V} \gamma 4^{+}$cells is shown (right). NS, not significant versus $\mathrm{V} \gamma 4^{+}$cells (unpaired Student's t-test). (b) Flow cytometry of IL-1R expression in LNs and joint-infiltrating cells from WT or II1rn ${ }^{-/-}$mice. Numbers refer to percentages in $\mathrm{CD} 3 \varepsilon^{+}$cells. Numbers in parenthesis represent percentages in CD3 $\varepsilon^{+} \gamma \delta$ TCR ${ }^{+}$cells (left). The percentage of IL-1R ${ }^{+}$cells among CD3 $\varepsilon^{+}$ $\gamma \delta \mathrm{TCR}^{+}$cells is indicated on the right. ${ }^{\star \star} P<0.01$; ${ }^{\star \star \star} P<0.001$ (versus WT mice) (unpaired Student's $t$-test). (c) FACS analysis of IL-1R and GFP expression on joint-infiltrating $\mathrm{CD}_{3} \varepsilon^{+} \gamma \delta \mathrm{TCR}^{+}$cells from WT, $\| 11 \mathrm{rn}^{-/-}$and $1117^{9 / 9} \| 11 \mathrm{rn}^{-/-}$mice. Numbers in parentheses represent percentage in $\mathrm{GFP}^{+} \gamma \delta \mathrm{TCR}^{+}$cells. (d,e) Flow cytometry of IL-1R expression in joint-infiltrating cells from II1rn ${ }^{-/}-$mice. Numbers refer to percentages in CD3 $\varepsilon^{+}$ $\gamma \delta \mathrm{TCR}^{+}$cells. Numbers in parentheses represent percentages in $\mathrm{V} \gamma 6^{+}\left(\mathrm{V} \gamma 4^{-}\right)$or $\mathrm{V} \gamma 4^{+}$cells (d, left). Quantification of IL-IR ${ }^{+}$cells $(\mathbf{d}$, right) and mean fluorescence intensity of IL-1R in $V \gamma 6^{+}$or $V \gamma 4^{+}$cells are indicated (e). ${ }^{\star} P<0.05$; ${ }^{\star \star \star} P<0.001$ (versus $V \gamma 4^{+}$cells) (unpaired Student's $t$-test). (f-h) Flow

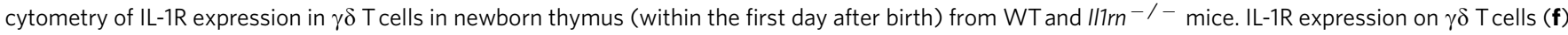
and on different $\mathrm{V} \gamma$ subsets $(\mathbf{g})$, and CCR2 and IL-1R expression on $\gamma \delta$ T cells $(\mathbf{h})$ are shown. Numbers refer to percentage in CD3 $\varepsilon^{+}$cells (f,h, top), or in $\mathrm{CD}_{\varepsilon} \varepsilon^{+} \gamma \delta \mathrm{TCR}^{+}$cells $\left(\mathbf{g}, \mathbf{h}\right.$, bottom). Numbers in parentheses represent percentage in $\gamma \delta \mathrm{TCR}^{+}$cells (f,h, top) or in IL- $1 \mathrm{R}^{+} \gamma \delta \mathrm{TCR}{ }^{+}$cells $(\mathbf{h}$, bottom) $(\mathbf{i}, \mathbf{j})$ qPCR analysis of the transcripts for IL-1 $\beta$ (II1b) (i) or IL-23 (II23p19) (j) in cells from joints, draining LNs (dLN), mesenteric LNs (mLN) and spleens (SP) from WT or $117 r^{-1}-$ mice. mRNA levels were normalized against Gapdh, and values are shown relative to $m L N$ of $W T$ mice. ${ }^{\star} P<0.05 ; N S$, not significant (versus WT mice) (unpaired Student's $t$-test). Data show mean \pm s.e.m. All data are representative of two or three independent experiments. 
arthritis) via CCR2-CCL2 interaction, development of arthritis was not completely suppressed by treatment with anti-CCL2 $\mathrm{mAb}$. Therefore, we could not completely exclude the possibility that these tissue-resident $\mathrm{V} \gamma 6^{+} \gamma \delta 17$ cells are also involved in development of arthritis.

$\gamma \delta 17$ cells have been observed in the peripheral tissues of several inflammatory diseases ${ }^{11,48,49}$, and the involvement of $\gamma \delta 17$ cells is suggested in some autoimmune models $5,7,11-13,24$. Innate immune cell-derived IL-17 has also been implicated in the pathogenesis of intestinal inflammatory diseases ${ }^{4}$. However, the mechanisms by which these IL-17-producing $\gamma \delta \mathrm{T}$ cells or innate immune cells are recruited to the inflammatory sites remain largely unknown. In this report, we showed that $\mathrm{CD}^{+}{ }^{+} \mathrm{T}$ cells determine the tissue specificity, and CD4 ${ }^{+}$T-cell-induced CCL2 recruits CCR2 ${ }^{+} \mathrm{V} \gamma 6^{+} \gamma \delta \mathrm{T}$ cells to the joints. Therefore, our model may explain how IL-17-producing $\gamma \delta \mathrm{T}$ cells or innate immune cells infiltrate local tissues and induce inflammation in other autoimmune diseases ${ }^{50}$. Taken together, our findings provide important insight into the immunological mechanisms driving tissue-specific autoimmune diseases, and may provide a clue for the development of novel therapies.

\section{Methods}

Mice. All mice, except C.B.-17 scid/scid mice (CLEA Japan, Tokyo, Japan), were on the BALB/cA genetic background. Ill $r^{-1-}$ mice were produced as described ${ }^{31,51}$ and backcrossed to BALB/CA (CLEA Japan) for nine generations. $I l 17^{g / g}$ mice were generated as shown in Supplementary Fig. 3a, and backcrossed to BALB/cA mice for eight generations. $I l 17^{g / g} I l 1 \mathrm{rn}^{-1-}$ mice were produced by crossing $I l 17^{g / g}$ mice with Ill1 $\mathrm{rn}^{-1-}$ mice. $\mathrm{Tcrd}^{-1-}$ mice were generated by Itohara et al. ${ }^{52}$. Cd4 $4^{-1-}$ mice were a gift from Dr. Fujii (RIKEN, Kanagawa, Japan). These mice were backcrossed to the BALB/cA mice for eight generations. Ill $b^{-1-}$ and $I l 1 a^{-1-} b^{-1-}$ mice were produced as described ${ }^{51}$. Illr1 $1^{-1-}$ mice were obtained from Immunex Corporation. Ill $7 a^{-1-}{\text { Ill } \mathrm{rn}^{-1-} \text { mice were generated as described }}^{32}$. Sex- and age-matched mice, usually at 8-12 weeks of age, were used for each experiment. In some experiments, newborn mice and younger (3-4 weeks old) or elder (24 weeks old) mice were also used as described in the figure legends. All mice were kept under specific pathogen-free conditions in environmentally controlled clean rooms at the Center for Experimental Medicine and Systems Biology, The Institute of Medical Science, The University of Tokyo, and Institute for Biomedical Sciences, Tokyo University of Science. All experiments were approved by the institutional ethical committees for animal experiments and the committees for gene manipulation experiments.

Clinical assessment of arthritis. Development of arthritis was monitored by macroscopic evaluation as described previously ${ }^{31}$. Briefly, each paw was graded as follows: 0 , no change; 1 , mild swelling; 2 , obvious swelling; 3 , severe swelling and ankylotic changes (maximum 12 points for individual mice).

Histological assessment of arthritis. Whole-ankle joints were fixed in $10 \%$ formalin in $0.001 \mathrm{M}$ phosphate buffer (pH 7.2), decalcified in 10\% EDTA and embedded in paraffin. Serial sections $(4 \mu \mathrm{m})$ were stained with haematoxylin and eosin. Each joint was graded on a scale of $0-3$ : 0 , normal; 1 , thickening and proliferation of the synovial lining, with slight inflammatory cell infiltration; 2, grade- 1 changes plus extensive synoviocyte proliferation and severe inflammatory cell infiltration; 3, grade- 2 changes plus pannus formation and bone erosion. Histological score of the ankle joint was estimated from the sum grade of both ankle joints (maximum 6 points for individual mice).

Immunofluorescence staining. For immunohistochemical analysis, hindlimbs were embedded in Super Cryoembedding Medium (Leica Microsystems Japan, Tokyo, Japan), and frozen sections $(5 \mu \mathrm{m})$ were generated. The sections were fixed in cold acetone for $5 \mathrm{~min}$ and blocked with $4 \%$ bovine serum albumin (Sigma, St Louis, MO, USA) and 5\% goat serum in PBS. Antibodies used were as follows: $2 \mu \mathrm{g} \mathrm{ml}^{-1}$ rabbit anti-mouse IL-17A polyclonal Ab (Abcam, ab9565-100, Cambridge, UK), $5 \mu \mathrm{g} \mathrm{ml}^{-1}$ hamster anti-mouse $\gamma \delta \mathrm{TCR} \mathrm{mAb}$ (GL3, BD Pharmingen, San Diego, CA, USA), $2.5 \mu \mathrm{g} \mathrm{ml}^{-1}$ Alexa Fluor 488-goat anti-rabbitIgG (Life Technologies, Carlsbad, CA, USA), and $2.5 \mu \mathrm{g} \mathrm{ml}^{-1}$ Cy3-goat antihamster IgG (Jackson ImmunoResearch, West Grove, PA, USA). Nuclei were stained with $0.5 \mu \mathrm{g} \mathrm{ml}^{-1} 4,6$-diamidino-2-phenylindole. The slides were visualized on a fluorescence microscope (Keyence, Osaka, Japan) and on an Olympus FV1000 Confocal Microscope, operated by the FluoView software (Olympus, Tokyo, Japan).
Isolation of joint-infiltrating cells. Ankle joints were cut out and digested with $2.4 \mathrm{mg} \mathrm{ml}^{-1}$ hyaluronidase (Sigma), $1 \mathrm{mg} \mathrm{ml}^{-1}$ collagenase (Sigma) in RPMI 1640 (Sigma) plus $10 \%$ foetal bovine serum (FBS) for $1 \mathrm{~h}$ at $37^{\circ} \mathrm{C}$. The cells were filtered through a cell strainer with a $70-\mu \mathrm{m}$ nylon mesh (Becton Dickinson, Franklin Lakes, NJ, USA) and washed with RPMI 1640 plus 10\% FBS.

Cell transfer. Purified $\gamma \delta \mathrm{T}$ cells $\left(8 \times 10^{5}\right.$ cells $), \mathrm{CD} 4^{+} \mathrm{T}$ cells $\left(2 \times 10^{7}\right.$ cells $)$ or Thy1.2 ${ }^{+} \mathrm{T}$ cells $\left(2 \times 10^{7}\right.$ cells) from LN (axillary, brachial, inguinal, popliteal and cervical) cells were suspended in $200 \mu \mathrm{l}$ sterile PBS and then injected intravascularly into scid/scid mice.

Antibody treatment. Non-arthritic Ill $\mathrm{rn}^{-1-}$ mice (4 weeks old) received twice weekly intraperitoneal injections of $400 \mu \mathrm{g}$ anti-TCR $\gamma \delta \mathrm{mAb}$ (UC7-13D5 (ref. 53), purified from hybridoma culture supernatant) or $250 \mu \mathrm{g}$ anti-CD4 mAb (GK1.5, purified from hybridoma culture supernatant provided by Dr Nariuchi (The University of Tokyo)). Isotype-matched Armenian hamster IgG (400 $\mu$ g per mouse; Innovate Research, Noida, India) was used as a control for UC7-13D5. Isotypematched rat IgG $(250 \mu \mathrm{g}$ per mouse; Thermo, Waltham, MA, USA) was used as a control for GK1.5. A dose of $200 \mu \mathrm{g}$ anti-CCL2 mAb (123616; R\&D Systems, Minneapolis, MN, USA), $200 \mu \mathrm{g}$ rat IgG2b isotype control (Fitzgerald, Sudbury Road Acton, MA, USA) or PBS alone was intraperitoneally injected into nonarthritic $I l 17^{g / g} / l 1 r^{-1-}$ mice at ages of 21, 24, 27 and 30 days.

Cell isolation. To examine LN cells by flow cytometry, axillary, brachial, inguinal and popliteal LNs were collected. To obtain FACS-purified $\gamma \delta \mathrm{T}$ cells, LN and/or spleen cells were first incubated with biotin-conjugated anti-mouse $\gamma \delta$ TCR mAb (GL3; \#13-5711, eBioscience, San Diego, CA, USA) (1/100 diluted) and then with MicroBeads conjugated to anti-biotin mAb (\#130-090-485, Miltenyi Biotec, Bergisch Gladbach, Germany) (1/8 diluted). Labelled cells were positively selected twice using autoMACS (Miltenyi Biotec). To purify whole-T cells and CD4 ${ }^{+} \mathrm{T}$ cells, LN and/or spleen cells were stained with Microbeads conjugated to antimouse Thy1.2 mAb (\#130-049-101, Miltenyi Biotec) and CD4 mAb (\#130-049201, Miltenyi Biotec), respectively (1/8 diluted), and separated using an autoMACS MACS-purified $\gamma \delta \mathrm{T}\left(\gamma \delta \mathrm{TCR}^{+} \mathrm{CD}^{+} \varepsilon^{+}\right)$cells and $\mathrm{GFP}^{+} \gamma \delta \mathrm{T}\left(\mathrm{GFP}^{+} \gamma \delta \mathrm{TCR}^{+}\right.$ $\mathrm{CD} 3 \varepsilon^{+}$) cells were further purified using a FACSAria (Becton Dickinson). FITCanti-mouse $\gamma \delta$ TCR mAb (UC7-13D5; eBioscience), PE-anti-mouse $\gamma \delta$ TCR mAb (GL3; BioLegend, San Diego, CA, USA), and APC/Cy7-anti-mouse CD3 $\varepsilon \mathrm{mAb}$ (145-2C11; BioLegend) (1/100 diluted) were used for labelling. The efficiency of these cell purifications was determined by flow cytometry.

Cell culture. For analysis of flow cytometry and concentrations of IL-17 in culture supernatants, cells from LNs and/or spleens were cultured for $72 \mathrm{~h}$ in RPMI 1640 containing $10 \%$ FBS with or without IL-1 $\beta\left(10 \mathrm{ng} \mathrm{ml}^{-1}\right)$ (PeproTech, Rocky Hill, NJ, USA), IL-23 (10 $\mathrm{ng} \mathrm{ml}^{-1}$ ) (R\&D Systems), IL-1Ra (200 $\mathrm{ng} \mathrm{ml}^{-1}$ ) (R\&D Systems) or cytokines at the indicated concentrations $\left(\mathrm{ng} \mathrm{ml}^{-1}\right)$ in the absence of $\gamma \delta$ TCR stimulation. For analysis of mRNA expression, $\gamma \delta^{+} \mathrm{CD} 3 \varepsilon^{+}$or $\gamma \delta^{-} \mathrm{CD} 3 \varepsilon^{+}$ $\mathrm{T}$ cells from spleens were purified using a FACSAria (Becton Dickinson) and cultured for $48 \mathrm{~h}$ with or without IL-1 $\beta\left(10 \mathrm{ng} \mathrm{ml}^{-1}\right)$ and IL-23 $\left(10 \mathrm{ng} \mathrm{ml}^{-1}\right)$.

Flow cytometry. Intracellular cytokine staining was performed as described previously ${ }^{54}$ after stimulation with $50 \mathrm{ng} \mathrm{ml}^{-1}$ phorbol myristate acetate (Sigma), $500 \mathrm{ng} \mathrm{ml}^{-1}$ ionomycin (Sigma) and $2 \mu \mathrm{M}$ monensin (Sigma) for $5 \mathrm{~h}$. For staining of cell-surface molecules, cells were first treated with anti-mouse CD16/CD32 mAbs (2.4G2, purified from hybridoma culture supernatant) in staining buffer (HBSS containing $2 \%$ FCS and $0.1 \%$ sodium azide) to block FcR binding, and then stained with antibodies ( $1 / 100$ diluted). A list of all antibodies used in the study is shown in Supplementary Table 2. For intracellular cytokine staining, cells were fixed with $4 \%$ paraformaldehyde and treated with a permeabilization buffer $(0.1 \%$ saponin (Sigma) in staining buffer), and then incubated with antibodies (1/100 diluted) against intracellular cytokine. 7-Aminoactinomycin D (Sigma) was used to stain dead cells. Cells were analysed on a FACSCanto II system (Becton Dickinson), and data were analysed with FlowJo software (Tree Star).

Measurement of cytokine. Concentrations of IL-17 in culture supernatants were determined by enzyme-linked immunosorbent assay using commercially available kits (Ready-Set-Go, eBioscience).

RT-PCR and real-time PCR. To prepare single cells for RNA expression analysis, draining LN, mesenteric LN and spleen were digested with $200 \mathrm{U} \mathrm{ml}^{-1}$ collagenase (Sigma) for $30 \mathrm{~min}$. Joints were digested with $200 \mathrm{Uml}^{-1}$ collagenase (Sigma) and $2.4 \mathrm{mgml}^{-1}$ hyaluronidase (Sigma). Next, these cells were filtered through a cell

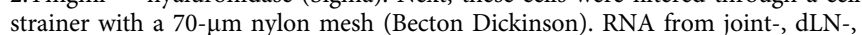
mLN- and spleen-derived single cells and RNA from cultured cells were extracted using the GenElute Mammalian Total RNA Miniprep Kit (Sigma). Tissue total RNA from joint, draining LN, spleen, thymus, colon, lung and liver was extracted using the Sepasol reagent (Nacalai Tesque, Kyoto, Japan). All RNA were denatured in the presence of an oligo dT primer and reverse transcribed using the High 
Capacity cDNA Reverse Transcription Kit (Applied Biosystems, Foster City, CA, USA). Quantitative real-time PCR was performed with a SYBR Green qPCR kit (Invitrogen, Carlsbad, CA, USA) and an iCycler system (Bio-Rad, Hercules, CA, USA) with the sets of primers described in Supplementary Table 3.

Statistics. Unless otherwise specified, all results are shown as means and s.e.m. Unpaired Student's $t$-tests were used to statistically analyse all results, except that Mann-Whitney's $U$-tests were used to evaluate disease severity and $\chi^{2}$-tests were used to evaluate disease incidence. Differences were considered significant at $P<0.05$.

\section{References}

1. Iwakura, Y., Ishigame, H., Saijo, S. \& Nakae, S. Functional specialization of interleukin-17 family members. Immunity 34, 149-162 (2011).

2. Kellner, H. Targeting interleukin-17 in patients with active rheumatoid arthritis: rationale and clinical potential. Ther. Adv. Musculoskelet. Dis. 5, 141-152 (2013)

3. Cua, D. J. \& Tato, C. M. Innate IL-17-producing cells: the sentinels of the immune system. Nat. Rev. Immunol. 10, 479-489 (2010).

4. Akitsu, A., Kakuta, S., Saijo, S. \& Iwakura, Y. Rag2-deficient IL-1 receptor antagonist-deficient mice are a novel colitis model in which innate lymphoid cell-derived IL-17 is involved in the pathogenesis. Exp. Anim. 63, 235-246 (2014).

5. Sutton, C. E. et al. Interleukin-1 and IL-23 induce innate IL-17 production from gammadelta $\mathrm{T}$ cells, amplifying Th17 responses and autoimmunity. Immunity 31, 331-341 (2009).

6. Petermann, F. et al. $\gamma \delta \mathrm{T}$ cells enhance autoimmunity by restraining regulatory $\mathrm{T}$ cell responses via an interleukin-23-dependent mechanism. Immunity 33, 351-363 (2010).

7. Roark, C. L. et al. Exacerbation of collagen-induced arthritis by oligoclonal, IL-17-producing gamma delta T cells. J. Immunol. 179, 5576-5583 (2007).

8. Park, S.-G. et al. T regulatory cells maintain intestinal homeostasis by suppressing $\gamma \delta \mathrm{T}$ cells. Immunity 33, 791-803 (2010).

9. Gray, E. E., Suzuki, K. \& Cyster, J. G. Cutting edge: identification of a motile IL-17-producing T cell population in the dermis. J. Immunol. 186, 6091-6095 (2011).

10. Sumaria, N. et al. Cutaneous immunosurveillance by self-renewing dermal gammadelta T cells. J. Exp. Med. 208, 505-518 (2011).

11. Cai, Y. et al. Pivotal role of dermal IL-17-producing $\gamma \delta \mathrm{T}$ cells in skin inflammation. Immunity 35, 596-610 (2011).

12. Gray, E. E. et al. Deficiency in IL-17-committed V $\gamma 4(+) \gamma \delta \mathrm{T}$ cells in a spontaneous Sox13-mutant CD45.1 $(+)$ congenic mouse substrain provides protection from dermatitis. Nat. Immunol. 14, 584-592 (2013).

13. Ito, Y. et al. Gamma/delta T cells are the predominant source of interleukin-17 in affected joints in collagen-induced arthritis, but not in rheumatoid arthritis. Arthritis Rheum. 60, 2294-2303 (2009).

14. Roark, C. L. et al. A canonical $\mathrm{V} \gamma 4 \mathrm{~V} \delta 4+\gamma \delta \mathrm{T}$ cell population with distinct stimulation requirements which promotes the Th17 response. Immunol. Res. 55, 217-230 (2012)

15. Shibata, K. et al. Identification of CD25 + gamma delta T cells as fetal thymusderived naturally occurring IL-17 producers. J. Immunol. 181, 5940-5947 (2008).

16. Ribot, J. C. et al. CD27 is a thymic determinant of the balance between interferon-gamma- and interleukin 17-producing gammadelta $\mathrm{T}$ cell subsets. Nat. Immunol. 10, 427-436 (2009).

17. Haas, J. D. et al. CCR6 and NK1.1 distinguish between IL-17A and IFNgamma-producing gammadelta effector T cells. Eur. J. Immunol. 39, 3488-3497 (2009).

18. Narayan, K. et al. Intrathymic programming of effector fates in three molecularly distinct $\gamma \delta$ T cell subtypes. Nat. Immunol. 13, 511-518 (2012).

19. Prinz, I., Silva-Santos, B. \& Pennington, D. J. Functional development of $\gamma \delta$ T cells. Eur. J. Immunol. 43, 1988-1994 (2013).

20. Duan, J., Chung, H., Troy, E. \& Kasper, D. L. Microbial colonization drives expansion of IL-1 receptor 1-expressing and IL-17-producing gamma/delta T cells. Cell Host Microbe 7, 140-150 (2010).

21. Laird, R. M., Laky, K. \& Hayes, S. M. Unexpected role for the B cell-specific Src family kinase B lymphoid kinase in the development of IL-17-producing T cells. J. Immunol. 185, 6518-6527 (2010).

22. Shibata, K. et al. Notch-Hes1 pathway is required for the development of IL-17producing $\gamma \delta$ T cells. Blood 118, 586-593 (2011).

23. Powolny-Budnicka, I. et al. RelA and RelB transcription factors in distinct thymocyte populations control lymphotoxin-dependent interleukin-17 production in $\gamma \delta \mathrm{T}$ cells. Immunity 34, 364-374 (2011).

24. Malhotra, N. et al. A network of high-mobility group box transcription factors programs innate interleukin-17 production. Immunity 38, 681-693 (2013).

25. Pereira, P. et al. Rearrangement and expression of $\mathrm{V} \gamma 1, \mathrm{~V} \gamma 2$ and $\mathrm{V} \gamma 3 \mathrm{TCR} \gamma$ genes in C57BL/6 mice. Int. Immunol. 8, 83-90 (1996).

26. O'Brien, R. L. \& Born, W. K. gammadelta T cell subsets: a link between TCR and function? Semin. Immunol. 22, 193-198 (2010).
27. Heilig, J. S. \& Tonegawa, S. Diversity of murine gamma genes and expression in fetal and adult T lymphocytes. Nature 322, 836-840 (1986).

28. Cai, Y. et al. Differential developmental requirement and peripheral regulation for dermal $\mathrm{V} \gamma 4$ and $\mathrm{V} \gamma 6 \mathrm{~T} 17$ cells in health and inflammation. Nat. Commun 5, 3986 (2014).

29. Itohara, S. et al. Homing of a gamma delta thymocyte subset with homogeneous T-cell receptors to mucosal epithelia. Nature 343, 754-757 (1990).

30. Bonneville, M., O’Brien, R. L. \& Born, W. K. Gammadelta T cell effector functions: a blend of innate programming and acquired plasticity. Nat. Rev. Immunol. 10, 467-478 (2010).

31. Horai, R. et al. Development of chronic inflammatory arthropathy resembling rheumatoid arthritis in interleukin 1 receptor antagonist-deficient mice. J. Exp. Med. 191, 313-320 (2000)

32. Nakae, S. et al. IL-17 production from activated T cells is required for the spontaneous development of destructive arthritis in mice deficient in IL-1 receptor antagonist. Proc. Natl Acad. Sci. USA 100, 5986-5990 (2003).

33. Horai, R. et al. TNF-alpha is crucial for the development of autoimmune arthritis in IL-1 receptor antagonist-deficient mice. J. Clin. Invest. 114, 1603-1611 (2004).

34. Fujikado, N., Saijo, S. \& Iwakura, Y. Identification of arthritis-related gene clusters by microarray analysis of two independent mouse models for rheumatoid arthritis. Arthritis Res. Ther. 8, R100 (2006).

35. Lalor, S. J. et al. Caspase-1-processed cytokines IL-1beta and IL-18 promote IL-17 production by gammadelta and CD4 T cells that mediate autoimmunity. J. Immunol. 186, 5738-5748 (2011).

36. Nakamura, R. et al. Tyk2-signaling plays an important role in host defense against Escherichia coli through IL-23-induced IL-17 production by gammadelta T cells. J. Immunol. 181, 2071-2075 (2008).

37. Hayes, S. M. \& Laird, R. M. Genetic requirements for the development and differentiation of interleukin-17-producing $\gamma \delta \mathrm{T}$ cells. Crit. Rev. Immunol. 32, 81-95 (2012).

38. Lafaille, J. J., DeCloux, A., Bonneville, M., Takagaki, Y. \& Tonegawa, S. Junctional sequences of $\mathrm{T}$ cell receptor gamma delta genes: implications for gamma delta $\mathrm{T}$ cell lineages and for a novel intermediate of V-(D)-J joining. Cell 59, 859-870 (1989).

39. Koenecke, C. et al. In vivo application of $\mathrm{mAb}$ directed against the $\gamma \delta \mathrm{TCR}$ does not deplete but generates 'invisible' $\gamma \delta \mathrm{T}$ cells. Eur. J. Immunol. 39, 372-379 (2009).

40. Shibata, K., Yamada, H., Hara, H., Kishihara, K. \& Yoshikai, Y. Resident Vdelta1 + gammadelta $\mathrm{T}$ cells control early infiltration of neutrophils after Escherichia coli infection via IL-17 production. J. Immunol. 178, 4466-4472 (2007).

41. Lança, T. et al. Protective role of the inflammatory CCR2/CCL2 chemokine pathway through recruitment of type 1 cytotoxic $\gamma \delta \mathrm{T}$ lymphocytes to tumor beds. J. Immunol. 190, 6673-6680 (2013).

42. Hirota, K. et al. Preferential recruitment of CCR6-expressing Th17 cells to inflamed joints via CCL20 in rheumatoid arthritis and its animal model. J. Exp. Med. 204, 2803-2812 (2007).

43. Reboldi, A. et al. C-C chemokine receptor 6-regulated entry of TH-17 cells into the CNS through the choroid plexus is required for the initiation of EAE. Nat. Immunol. 10, 514-523 (2009).

44. Arima, Y. et al. Regional neural activation defines a gateway for autoreactive $\mathrm{T}$ cells to cross the blood-brain barrier. Cell 148, 447-457 (2012).

45. Reddy, S. et al. An autoinflammatory disease due to homozygous deletion of the IL1RN locus. N. Engl. J. Med. 360, 2438-2444 (2009).

46. Aksentijevich, I. et al. An autoinflammatory disease with deficiency of the interleukin-1-receptor antagonist. N. Engl. J. Med. 360, 2426-2437 (2009).

47. Haas, J. D. et al. Development of interleukin-17-producing $\gamma \delta \mathrm{T}$ cells is restricted to a functional embryonic wave. Immunity 37, 48-59 (2012).

48. Kenna, T. J. et al. Enrichment of circulating interleukin-17-secreting interleukin-23 receptor-positive $\gamma / \delta \mathrm{T}$ cells in patients with active ankylosing spondylitis. Arthritis Rheum. 64, 1420-1429 (2012).

49. Caccamo, N. et al. Differentiation, phenotype, and function of interleukin-17producing human V $\gamma 9 \mathrm{~V} \delta 2 \mathrm{~T}$ cells. Blood 118, 129-138 (2011).

50. Hueber, A. J. et al. Mast cells express IL-17A in rheumatoid arthritis synovium. J. Immunol. 184, 3336-3340 (2010).

51. Horai, R. et al. Production of mice deficient in genes for interleukin (IL)1alpha, IL-1beta, IL-1alpha/beta, and IL-1 receptor antagonist shows that IL-1beta is crucial in turpentine-induced fever development and glucocorticoid secretion. J. Exp. Med. 187, 1463-1475 (1998).

52. Itohara, S. et al. T cell receptor delta gene mutant mice: independent generation of alpha beta $\mathrm{T}$ cells and programmed rearrangements of gamma delta TCR genes. Cell 72, 337-348 (1993).

53. Houlden, B. A. et al. A TCR gamma delta cell recognizing a novel TL-encoded gene product. Cold Spring Harb. Symp. Quant. Biol. 54(Pt 1): 45-55 (1989).

54. Komiyama, Y. et al. IL-17 plays an important role in the development of experimental autoimmune encephalomyelitis. J. Immunol. 177, 566-573 (2006). 


\section{Acknowledgements}

We thank S. Fujii (RIKEN, Kanagawa, Japan) for providing us with $C d 4^{-/-}$mice. Y. Ishii and A. Fujita (FACS Core Laboratory, The Institute of Medical Science, The University of Tokyo, Tokyo, Japan) for cell sorting; H. Saito (The University of Tokyo) for studentship support; K. Shibata (Kyushu University, Fukuoka, Japan) for reading the manuscript and for valuable discussion; A. Seno for technical assistance in designing the figures; and all members of our laboratory for excellent animal care. This work was supported by CREST (Y.I.), Grants-in-Aid from the Ministry of Education, Culture, Sports, Science and Technology of Japan (Y.I.), the Scientific Technique Research Promotion Program for Agriculture, Forestry, Fisheries and Food Industry (Y.I.) and the JSPS (A.A.).

\section{Author contributions}

A.A. made the principal contribution to all aspects of this work. H.I., S.K. and S.S. gave advice and technical support. S.-H.C., S.I. and K.S. provided technical support. S.K. and Y.L. provided technical support for the generation of $I l 17^{g / g}$ mice. M.U. and G.M. provided anti-V $\gamma 7 \mathrm{mAb}$. Y.Y. provided anti- $\gamma \delta \mathrm{TCR} \mathrm{mAb}$-producing hybridoma and $\mathrm{Tcrd}^{-1}$

- mice. Y.I. organized and supervised the project and edited the draft manuscript.

\section{Additional information}

Supplementary Information accompanies this paper at http://www.nature.com/ naturecommunications

Competing financial interests: The authors declare no competing financial interests.

Reprints and permission information is available online at http://npg.nature.com/ reprintsandpermissions/

How to cite this article: Akitsu, A. et al. IL-1 receptor antagonist-deficient mice develop autoimmune arthritis due to intrinsic activation of IL-17-producing CCR2 ${ }^{+} \mathrm{V}^{\gamma} 6{ }^{+} \gamma \delta$ T cells. Nat. Commun. 6:7464 doi: 10.1038/ncomms8464 (2015).

\section{(c) (i)}

This work is licensed under a Creative Commons Attribution 4.0 International License. The images or other third party material in this article are included in the article's Creative Commons license, unless indicated otherwise in the credit line; if the material is not included under the Creative Commons license, users will need to obtain permission from the license holder to reproduce the material. To view a copy of this license, visit http://creativecommons.org/licenses/by/4.0/ 